\title{
Amino acid composition of nanofibrillar self-assembling peptide hydrogels affects responses of periodontal tissue cells in vitro
}

This article was published in the following Dove Press journal: International Journal of Nanomedicine

Franziska Koch, ${ }^{1-3}$ Anne Wolff, ${ }^{2}$ Stephanie Mathes, ${ }^{4}$ Uwe Pieles,' Sina S Saxer,' Bernd Kreikemeyer, ${ }^{3}$ Kirsten Peters ${ }^{2}$

'Institute for Chemistry and Bioanalytics, School of Life Sciences, University of Applied Sciences and Arts Northwestern Switzerland, Muttenz, Switzerland; ${ }^{2}$ Department of Cell Biology, University Medicine Rostock, Rostock, Germany; ${ }^{3}$ Institute of Medical Microbiology, Virology and Hygiene, University Medicine Rostock, Rostock, Germany; ${ }^{4}$ Department for Chemistry and Biotechnology, Tissue Engineering, Zurich University of Applied Sciences, Wädenswil, Switzerland

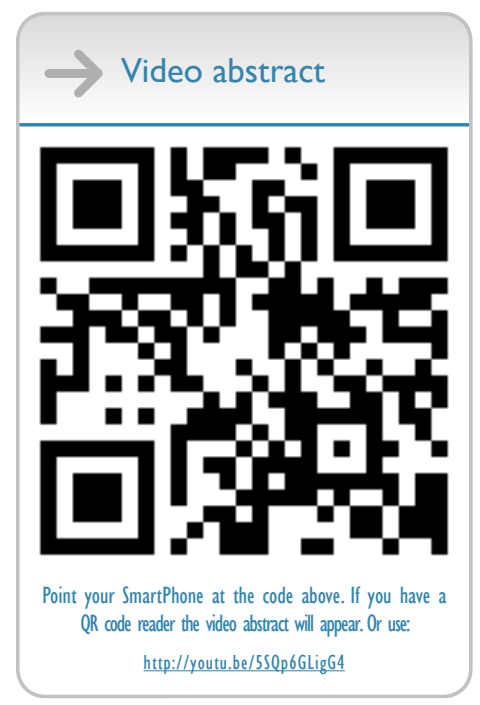

Correspondence: Kirsten Peters University Medicine Rostock, Department of Cell Biology, Schillingallee 69, I8057 Rostock (DE), Germany

Tel +49 38I 4947757

Email kirsten.peters@med.uni.rostock.de
Background: The regeneration of tissue defects at the interface between soft and hard tissue, eg, in the periodontium, poses a challenge due to the divergent tissue requirements. A class of biomaterials that may support the regeneration at the soft-to-hard tissue interface are self-assembling peptides (SAPs), as their physicochemical and mechanical properties can be rationally designed to meet tissue requirements.

Materials and methods: In this work, we investigated the effect of two single-component and two complementary $\beta$-sheet forming SAP systems on their hydrogel properties such as nanofibrillar architecture, surface charge, and protein adsorption as well as their influence on cell adhesion, morphology, growth, and differentiation.

Results: We showed that these four 11-amino acid SAP (P11-SAP) hydrogels possessed physicochemical characteristics dependent on their amino acid composition that allowed variabilities in nanofibrillar network architecture, surface charge, and protein adsorption (eg, the single-component systems demonstrated an $\sim 30 \%$ higher porosity and an almost 2 -fold higher protein adsorption compared with the complementary systems). Cytocompatibility studies revealed similar results for cells cultured on the four P11-SAP hydrogels compared with cells on standard cell culture surfaces. The singlecomponent P11-SAP systems showed a 1.7-fold increase in cell adhesion and cellular growth compared with the complementary P11-SAP systems. Moreover, significantly enhanced osteogenic differentiation of human calvarial osteoblasts was detected for the single-component P11-SAP system hydrogels compared with standard cell cultures.

Conclusion: Thus, single-component system P11-SAP hydrogels can be assessed as suitable scaffolds for periodontal regeneration therapy, as they provide adjustable, extracellular matrixmimetic nanofibrillar architecture and favorable cellular interaction with periodontal cells.

Keywords: self-assembling peptides, SAPs, P11-SAP hydrogels, surface charge, protein adsorption, cell proliferation, osteogenic differentiation, periodontal tissue regeneration

\section{Introduction}

The development of therapies for the regeneration of tissue defects at the interface between soft and hard tissue (eg, ligament-to-bone within the periodontium) poses a challenge due to the diverging tissue requirements. The periodontium consists of the gingiva, periodontal ligament, cementum, and alveolar bone. ${ }^{1}$ Periodontal diseases lead to the breakdown of the periodontium by bacterial infection, if untreated ultimately resulting in tooth loss. ${ }^{2}$ Several techniques have been developed, which aim to support natural periodontal regeneration such as guided tissue regeneration and bone grafting, either with or without the use of enamel matrix derivative or growth factors. ${ }^{3}$ Yet, these different therapeutic options frequently lead to unsatisfactory clinical results 
(ie, tooth loss), and thus, a medical need remains for the development of biomaterials specifically designed for the conditions at the soft-to-hard tissue interface. It is known that the physicochemical characteristics of biomaterials, such as surface charge and scaffold architecture, can control cellular responses and thus influence tissue regeneration. ${ }^{4-7}$ For example, cell growth, cell migration, and cell differentiation are influenced by the aforementioned parameters. ${ }^{5,8,9}$ Thus, the knowledge about possible coherences between the physicochemical characteristics and the resulting cellular reactions can be decisive for the development of suitable biomaterials. Soft-to-hard tissue interfaces therefore require an ambilateral adaptation to physicochemical and mechanical characteristics of both interfaces.

A class of material that could meet the requirements at the soft-to-hard tissue interface are self-assembling peptides (SAPs), as their physicochemical and mechanical properties can be tuned by rational design. ${ }^{10}$ SAPs are shown to exhibit an adjustable biodegradability, a lack of immunogenicity, and a possibility to be applied with minimal invasive procedures (eg, injection into the periodontal pocket). ${ }^{11}$ Previous reports have provided a first indication of the suitability of SAPs for periodontal therapy. For example, RADA16, a 16-amino acid $\beta$-sheet-forming SAP, is reported to facilitate attachment, proliferation, and migration of human periodontal ligament fibroblasts (HPDLFs) and induce the deposition of collagen type I and III, the main components of the periodontal ligament. ${ }^{12}$ An animal study investigating the efficacy of RADA16 in periodontal regeneration demonstrated new bone and periodontal ligament-like collagen bundle formation, indicating periodontal regeneration. ${ }^{13}$ Yet, despite the promising results, no SAP is available for treatment in the clinic.

Recently, the 11-amino acid SAPs (P11-SAPs) gained attention for the regeneration of dental hard tissue, as they have been shown to deposit calcium phosphate. ${ }^{14-16}$ Moreover, it was demonstrated that these P11-SAPs form antiparallel $\beta$-sheet structures as well as higher-order structures such as fibrils and fibers under physiological conditions. ${ }^{17-19}$ Thus, fibrillar P11-SAP hydrogels are suitable as scaffolds for tissue regeneration as they can self-assemble under physiological conditions and have adaptable SAP hydrogel stiffnesses brought on by modulating the peptide concentration and buffer composition. ${ }^{17,19,20}$ In animal studies, P11-SAP scaffolds have been shown to lack immunogenicity ${ }^{21}$ and to possess a high biocompatibility. ${ }^{11,22}$ Hence, these P11-SAPs are promising candidates for a detailed in vitro evaluation of their suitability as scaffolds in soft and hard tissue regeneration. For this purpose, we tested four different P11-SAP systems. Two complementary systems (P11-13/14 and P1128/29) were selected for their dual-syringe application mode, their favorable assembly kinetics, and their capacity as drug delivery carriers. Two single-component systems (P11-4, P11-8) were selected because they had previously been demonstrated as suitable matrices for mineralization. ${ }^{23-25}$

To this end, we investigated several physicochemical properties of P11-SAPs scaffolds that are known to govern their interactions with cells, ie, nanofibrillar architecture, surface charge, and swelling ratio in the context of their composition. As a consecutive step, the impact of the four P11-SAP scaffolds was tested with respect to their biocompatibility, cell morphology, adhesion, proliferation, and osteogenic differentiation by using cells involved in the periodontal regeneration (ie, HPDLFs, human calvarial osteoblasts [HCO]).

\section{Materials and methods Peptide hydrogel preparation}

P11-SAPs, P11-4 (sequence: Table 1, peptide content 95\%, ammonium salt), P11-8 [sequence: Table 1, peptide content 84.4\%, trifluoroacetic acid (TFA) salt], P11-13 (sequence: Table 1, peptide content 78.5\%, ammonium salt), P11-14 (sequence: Table 1, peptide content 74.6\%, TFA salt), P11-28 (sequence: Table 1, peptide content 70.7\%, TFA salt), and P11-29 (sequence: Table 1, peptide content 89.0\%, ammonium salt) were purchased from CS Bio Company, Menlo Park, CA, USA. Release analytics were performed by HPLC and mass spectroscopy. Sodium chloride $(\mathrm{NaCl})$ and Trizma ${ }^{\circledR}$ bases used for peptide buffer preparation were purchased

Table I PI I-SAP composition and preparations in four different solutions

\begin{tabular}{|c|c|c|c|c|}
\hline Peptide & Peptide composition & Peptide net charge & Solution A & Solution B \\
\hline PII-4 & QQRFEWEFEQQ & -2 & 55 mM Tris, pH 8 & $55 \mathrm{mM}$ Tris, $192 \mathrm{mM} \mathrm{NaCl}, \mathrm{pH} 6.8$ \\
\hline PII-8 & QQRFOWOFEQQ & +2 & $\mathrm{H}_{2} \mathrm{O}, \mathrm{pH} 6$ & $55 \mathrm{mM}$ Tris, $236 \mathrm{mM} \mathrm{NaCl}, \mathrm{pH} 8.5$ \\
\hline \multirow{2}{*}{$\begin{array}{l}\text { PII-13 } \\
\text { PII-29 }\end{array}$} & EQEFEWEFEQE & \multirow[t]{2}{*}{-2} & \multirow[t]{2}{*}{100 mM Tris, 52 mM NaCl, pH 8} & \\
\hline & QQEFEWEFEQQ & & & \\
\hline \multirow{2}{*}{$\begin{array}{l}\text { PII-I4 } \\
\text { PII-28 }\end{array}$} & QQOFOWOFOQQ & \multirow[t]{2}{*}{+2} & \multirow[t]{2}{*}{$55 \mathrm{mM}$ Tris, $96 \mathrm{mM} \mathrm{NaCl}, \mathrm{pH} 7$} & \\
\hline & OQOFOWOFOQO & & & \\
\hline
\end{tabular}


from Sigma-Aldrich, Buchs, Switzerland. For each peptide system, buffer composition was adjusted to their specific physicochemical properties (Table 1).

Single-component P11-SAP hydrogels (P11-4 and P11-8) were prepared by dissolving the lyophilized peptide powder in $100 \mu \mathrm{L}$ of solution $\mathrm{A}$, thus obtaining a monomeric peptide solution. To induce self-assembly, $100 \mu \mathrm{L}$ of solution B was added to the peptide monomer solution, adjusting the $\mathrm{pH}$ and thereby triggering self-assembly. Complementary P11SAPs (P11-13/14 and P11-28/29) were dissolved separately in $100 \mu \mathrm{L}$ of their peptide-specific solutions. Peptide pairs were mixed 1:1; eg, $100 \mu \mathrm{L}$ P11-13 plus $100 \mu \mathrm{L}$ P11-14 at equimolar concentrations to obtain a final volume of $200 \mu \mathrm{L} \mathrm{P11-13/14} \mathrm{and} \mathrm{a} \mathrm{concentration} \mathrm{of} 10 \mathrm{mg} / \mathrm{mL}$. A final concentration of $140 \mathrm{mM}$ and a $\mathrm{pH}$ of 7.2-7.4 were adjusted for P11-4, P11-13/14, and P11-28/29 using 0.1 M $\mathrm{NaOH}$ or $0.1 \mathrm{M} \mathrm{HCl}$ (Sigma-Aldrich). For P11-8, a pH of 7.8-8.0 was adjusted using $0.1 \mathrm{M} \mathrm{NaOH}$. For cell culture experiments, P11-SAP hydrogels were assembled overnight at $37^{\circ} \mathrm{C}$, followed by 15 minutes of UV light exposure for hydrogel sterilization.

\section{Analysis of nanofibrillar PII-SAP hydrogels \\ Scanning electron microscopy (SEM) studies}

To analyze the nanofibrillar network architecture of the P11-SAP hydrogels in detail, SEM images, which had been previously prepared and recorded by us in the study of Koch et al, ${ }^{17}$ were further processed by Image J version 2.0 using the DiameterJ plugin. ${ }^{26}$ Therefore, the images were converted to black (background) and white (fibers) by the segmentation process and subsequently the M5 algorithm was applied. Parameters such as porosity, intersection density, and fiber diameter were calculated as a function of the DiameterJ software based on the segmented SEM images. Five SEM images were analyzed for each peptide system.

\section{Zeta potential measurements for surface charge}

Zeta potential measurements were performed with the Zetasizer Nanoseries (Malvern Instruments, Malvern, UK) to compare theoretical calculated SAP net charges with the monomer and fibril charges present at a $\mathrm{pH}$ of 3, 7, and 12 in $0.001 \mathrm{M} \mathrm{NaCl}$. The $\mathrm{pH}$ of the different SAP solutions was adjusted by using $0.1 \mathrm{M} \mathrm{NaOH}$ and $0.1 \mathrm{M} \mathrm{HCl}$. P11-SAP concentrations of $3 \mathrm{mg} / \mathrm{mL}$ together with a Zetasizer Clear Disposable Cell (Malvern) were used. Measurements were performed at room temperature (RT) directly after adjusting the $\mathrm{pH}$. All experiments were done in triplicate.

\section{Swelling ratio}

To determine the P11-SAP hydrogel swelling behavior, samples were prepared at a peptide concentration of $15 \mathrm{mg} / \mathrm{mL}$ in $55 \mathrm{mM}$ Tris buffer with additional $\mathrm{NaCl}$ (final salt concentration $140 \mathrm{mM}$ ) and were allowed to assemble overnight. PBS (Sigma-Aldrich) was added, and the hydrogels were incubated for 24 hours at RT. Samples were weighed before and after the swelling process to evaluate water uptake into the P11-SAP hydrogels. Finally, peptide hydrogels were lyophilized overnight with a Christ Lyophilizer (Christ ${ }^{\circledR}$ freeze dryer alpha 1-4 LSC, Germany) at $-50^{\circ} \mathrm{C}$ and $1.0 \times 10^{-3} \mathrm{~Pa}$ and weighed again to calculate the swelling ratios according to:

$$
\mathrm{SW}=\frac{\mathrm{Ws}-\mathrm{Wd}}{\mathrm{Wd}}
$$

where Ws and Wd are the weights of the hydrogels in the equilibrium swelling and in the freeze-dried state, respectively. ${ }^{27}$

\section{Cell culture experiments}

HPDLF and HCO were cultured up to $80 \%-90 \%$ confluency and in fibroblast or osteoblast medium (cells and media from ScienCell, Carlsbad, CA, USA), respectively, before they were passaged using $0.5 \%$ Trypsin-EDTA solution (Gibco ${ }^{\mathrm{TM}}$ by Life Technologies, Darmstadt, Germany). One passage took 5 days. Both cell types were used at passage 4 for every experiment. Cell culture medium was changed at passage 3 to the expansion medium DMEM (Gibco $^{\mathrm{TM}}$ by Life Technologies) containing 10\% FBS (PAN-Biotech, Germany) and 1\% Penicillin (P)/Streptomycin (S) (Gibco ${ }^{\circledR}$ by Life Technologies) 2 days before they were seeded onto P11-SAP hydrogels.

\section{Cytocompatibility testing of PI I-SAP monomers and PII-SAP hydrogel extracts}

To assess cell viability, P11-SAP monomer solutions were prepared at $1 \mathrm{mg} / \mathrm{mL}$ and $5 \mathrm{mg} / \mathrm{mL}$ in the respective cell culture media. HPDLF and HCO cells $(6,800$ cells per well) were incubated in a 96 -well plate with peptide-containing medium for 24 hours at $37^{\circ} \mathrm{C}$ and analyzed afterward by using PrestoBlue $^{\circledR}$ Viability Reagent (Invitrogen-Life Technologies). For this purpose, the cell culture supernatants were removed, and the PrestoBlue Viability Reagent was added to the cells, diluted 1:10 with cell culture medium, and incubated for 3 hours at $37^{\circ} \mathrm{C}$. Finally, $100 \mu \mathrm{L}$ of supernatant was placed into a new, 96-well plate and fluorescence was measured at 
$560 \mathrm{~nm}$ excitation and $590 \mathrm{~nm}$ emission with a fluorescence microplate reader (TECAN, Crailsheim, Germany).

The indirect cytotoxicity of P11-SAP hydrogel extracts was assessed according to the ISO 10993-5 standard test protocol. P11-SAP hydrogels were prepared at $20 \mathrm{mg} / \mathrm{mL}$, as described above. P11-SAP hydrogels were incubated with $230 \mu \mathrm{L}$ of the respective cell culture media for 24 hours at $37^{\circ} \mathrm{C}$. Afterward, cell culture medium extracts were removed and further diluted in steps with fresh medium to achieve a final extract concentration of 10,5 , and $1 \mathrm{mg} / \mathrm{mL}$. One hundred microliters per well of the original extract $(20 \mathrm{mg} / \mathrm{mL})$ and the diluted extracts were added to 6,800 cells (either HPDLF or HCO) per well of a 96-well plate (F-bottom, crystal clear, Greiner Bio-One, Frickenhausen, Germany). The standard cell cultures were grown on tissue culture polystyrene (TCPS) as a control. Sample extracts and controls were exposed to the cells for 24 hours at $37^{\circ} \mathrm{C}$. Finally, lactate dehydrogenase (LDH) leakage from damaged cells and therefore cell vitality was determined by an LDH cytotoxicity test kit (Roche, Mannheim, Germany) according to the manufacturer's protocol. LDH activity was normalized by the quantification of the cell amount using crystal violet (Merck, Darmstadt, Germany) staining.

\section{Cellular phenotype and cell adhesion in contact with PI I-SAP hydrogels}

To investigate the cellular phenotype, $200 \mu \mathrm{L}$ of P11-SAP hydrogels was prepared at $15 \mathrm{mg} / \mathrm{mL}$ for P11-4/P11-8 and $10 \mathrm{mg} / \mathrm{mL}$ for P11-13/14/P11-28/29 in chamber slides (SPL Life Sciences, Gyeonggi-do, Korea) and were incubated overnight. Cells cultured on the uncoated chamber slide surfaces were taken as a control.

P11-SAP hydrogels were equilibrated with DMEM+10\% FBS for 1 hour at $37^{\circ} \mathrm{C}$. Afterward, 10,000 cells per well (HPDLF and HCO) were seeded in DMEM medium. After 24 hours, cells were washed twice with Dulbecco's PBS (DPBS) and fixed with 4\% paraformaldehyde (Sigma-Aldrich, Taufkirchen, Germany) solution in DPBS for 20 minutes. To permeabilize the cell membranes, $0.1 \%$ Triton-X100-PBS (Fluka) was added for 5 minutes. After washing the cells twice with DPBS, cells were incubated with 1\% BSA (Cell Signaling Technology, Frankfurt am Main, Germany) solution in DPBS for 30 minutes to reduce unspecific binding. Finally, Rhodamine-conjugated phalloidin (Thermo Fisher Scientific, Reinach, Switzerland) was added 1:40 (stock 1:1,000 in methanol) in PBS and incubated for 30 minutes in the dark. Cells were then washed three times prior to visualization with a confocal laser scanning microscope (LSM 780, Zeiss, Jena, Germany).
Furthermore, the adhesion of HPDLF and HCO cells on P11-SAP hydrogels was evaluated. Cells were seeded onto the $70 \mu \mathrm{L}$ of P11-SAP hydrogel surfaces at 6,800 cells $/ \mathrm{cm}^{2}$ in DMEM. For the indirect quantification of the number of adhered cells, the supernatant including the nonadhered cells was carefully removed and the metabolic activity of the surface/hydrogel adhered cells was quantified using the PrestoBlue Viability Reagent as described by the manufacturer.

\section{Metabolic activity of HPDLF and HCO}

P11-SAP hydrogels (prepared at $15 \mathrm{mg} / \mathrm{mL}$ for P11-4/P11-8 and $10 \mathrm{mg} / \mathrm{mL}$ for P11-13/14/P11-28/29) were prepared in 96-well plates according to Table 1 and seeded with 6,800 cells $/ \mathrm{cm}^{2}$ (HPDLF and HCO) in DMEM supplemented with $10 \% \mathrm{FBS}$ and $1 \% \mathrm{P} / \mathrm{S}$. Cellularized P11-SAP hydrogels were cultured up to 14 days, whereby every third day the medium was replaced. Metabolic activity was assessed after $1,3,7$, and 14 days of culturing using a resazurin-based, redox-sensitive assay PrestoBlue Viability Reagent.

\section{Protein adsorption on PI I-SAP hydrogels}

and its influence on cell phenotype

To investigate the cell phenotype as a function of the electrostatic interaction and the protein adsorption, $200 \mu \mathrm{L}$ of P11-SAP hydrogels were prepared in chamber slides (SPL Life Sciences) at $15 \mathrm{mg} / \mathrm{mL}$ for the single-component SAPs (P11-4 and P11-8) and at $10 \mathrm{mg} / \mathrm{mL}$ for the complementary SAPs (P11-13/14 and P11-28/29). P11-SAP hydrogels were equilibrated with either serum-free DMEM or fibronectin(from bovine plasma, Sigma-Aldrich) supplemented DPBS (PAN-Biotech) $(300 \mu \mathrm{g} / \mathrm{mL})$ for 1 hour at $37^{\circ} \mathrm{C}$. Cells were seeded at a density of 10,000 per well and stained for actin cytoskeleton as described in "Cellular phenotype and cell adhesion in contact to P11-SAP hydrogels", cellular phenotype and adhesion. For the quantification of fibronectin adsorption on the P11-SAP hydrogels tested, hydrogels were prepared in SPL slides as described above. Fibronectin $(300 \mu \mathrm{g} / \mathrm{mL}$, DPBS $)$ solution was incubated on peptide hydrogels for 1 hour at $37^{\circ} \mathrm{C}$. P11-SAP hydrogels were then washed twice with ultrapure water to remove unbound fibronectin before being first mechanically disintegrated by pipetting up and down with a high viscosity pipet (Gilson, Mettmenstetten, Switzerland) and finally chemically disintegrated using $1 \mathrm{M} \mathrm{NaOH}$ or $1 \mathrm{M} \mathrm{HCL}$. De-assembled P11SAP hydrogels were homogenized three times for 10 seconds on ice using a Branson Sonifier 250 (Heinemann, Schwäbisch Gmünd, Germany). Afterward, samples were centrifuged 
at $12,000 \mathrm{rpm}$ for 10 minutes at $4^{\circ} \mathrm{C}$. To determine the amount of fibronectin, $10 \mu \mathrm{L}$ of each sample was measured with the Qubit ${ }^{\circledR}$ Protein Assay (Thermo Fisher Scientific). As a $100 \%$ control, $10 \mu \mathrm{L}$ of the initial fibronectin solution was measured. All experiments were done at least in triplicate. As a subsequent experiment, bound fibronectin on the complementary SAPs P11-13/14 and P11-28/29 (prepared at $100 \mu \mathrm{g} / \mathrm{mL}$ ) was visualized by a primary rabbit polyclonal antifibronectin antibody (1:100, DPBS, Abcam, Cambridge, UK) incubated overnight at $4^{\circ} \mathrm{C}$, followed by the incubation with a goat antirabbit-Alexa Fluor 594-conjugated antibody (1:100, DPBS, Abcam). Samples were washed with DPBS prior to, in between, and after antibody incubation. Samples were assessed with a confocal laser scanning microscope (LSM 780, Zeiss) using a 20× objective.

\section{Cellular phenotype on hydrogels with different stiffnesses}

To investigate cell phenotype as a function of reduced P11SAP hydrogel stiffness, P11-13/14 and P11-28/29 were prepared at 5 and $10 \mathrm{mg} / \mathrm{mL}$ and first measured with an oscillatory amplitude sweep test using an Anton Paar MCR301 (Anton Paar, Buchs, Switzerland) rheometer equipped with a $10 \mathrm{~mm}$ diameter stainless steel parallel plate geometry at a $0.9 \mathrm{~mm}$ measuring gap. To determine the HPDLF and HCO phenotype, 10,000 cells of each cell type were incubated in chamber slides (SPL Life Sciences) for 24 hours on $200 \mu \mathrm{L}$ of P11-13/14 and P11-28/29 P11-SAP hydrogels (5 mg/mL and $10 \mathrm{mg} / \mathrm{mL}$ ). Staining for actin cytoskeleton was performed according to section "Cellular phenotype and cell adhesion in contact to P11-SAP hydrogels.”

\section{Analysis of osteogenic differentiation Quantification of ALP activity}

The ALP activity was analyzed by the colorimetric ALP assay kit (Abcam). Cell lysate samples at 1, 7, and 14 days of incubation on P11-4 and P11-8 peptide hydrogels (15 mg/mL) were investigated (lysate harvesting as described for the Milliplex assay above). Staining was performed according to the manufacturer's instructions. The absorbance was read at $450 \mathrm{~nm}$ with a fluorescence microplate reader (TECAN).

\section{Quantification of osteoprotegerin (OPG)}

For the quantification of the osteogenic marker OPG, $200 \mu \mathrm{L}$ P11-4 and P11-8, P11-SAP hydrogels were prepared at $15 \mathrm{mg} / \mathrm{mL}$ in chamber slides. Complementary P11-SAP hydrogels (P11-13/14; P11-28/29) were not considered as appropriate for further studies due to the lower metabolic activity after 14 days of $\mathrm{HCO}$ culture. $\mathrm{HCO}$ were seeded on top of the P11-SAP hydrogels at a density of 10,000 cells $/ \mathrm{cm}^{2}$. Osteogenic differentiation of HCO was induced by exposure to osteogenic differentiation medium containing DMEM 10\% FBS, 1\% P/S, $1 \mu \mathrm{M}$ dexamethasone (Sigma-Aldrich), $250 \mu \mathrm{g} / \mathrm{mL}$ ascorbate (Sigma-Aldrich), and $10 \mathrm{mM} \beta$-glycerophosphate (Sigma-Aldrich).

The medium was changed every 2 to 3 days. Undifferentiated $\mathrm{HCO}$ grown in expansion medium was used as control. After 1, 7, and 14 days, cell culture supernatants were collected and stored at $-20^{\circ} \mathrm{C}$ for further analysis. To analyze the total secretion of osteogenic markers, $130 \mu \mathrm{L}$ of P11-SAP hydrogel matrices containing differentiated and undifferentiated HCOs were dissolved by transferring the gels in $1.5 \mathrm{~mL}$ low protein-binding tubes (Eppendorf, Hamburg, Germany) with a cell scraper, followed by the addition of $130 \mu \mathrm{L}$ of cell lysis buffer and either $1 \mu \mathrm{L}$ of $1 \mathrm{M} \mathrm{NaOH}$ to de-assemble P11-4 hydrogels or $1 \mathrm{M} \mathrm{HCl}$ to de-assemble P11-8 hydrogels. To ensure complete cell lysis, the tubes were agitated for 30 minutes at $4^{\circ} \mathrm{C}$. Afterward, cell lysates containing de-assembled P11-SAP hydrogels were homogenized (Branson Sonifier 250, Heinemann) three times for $10 \mathrm{sec}-$ onds on ice. Cell debris was eliminated by centrifugation at $12,000 \mathrm{rpm}$ for 10 minutes at $4^{\circ} \mathrm{C}$. Finally, cell culture supernatants and supernatants extracted from cell lysates were thawed and analyzed by the Milliplex MAP Human Bone Magnetic Bead Kit (Merck Millipore, Germany) according the manufacturer's protocol. Samples were measured with a Bio-Plex 200 system (Bio-Rad, Germany).

\section{Quantification of mineralization}

For the quantification of the calcium deposition of HCOs on P11-4 and P11-8, P11-SAP hydrogels, cells were cultured up to 30 days in osteogenic differentiation medium or expansion medium as a negative control. P11-SAP hydrogels were prepared in a 96-well plate as described in "Metabolic activity of HPDLF and HCO" (metabolic activity). Medium was replaced every third day during cultivation. After 1 and 30 days, the medium was removed, and the cell-seeded P11SAP hydrogels were rinsed twice with PBS. Subsequently, the hydrogels were fixed with 4\% PFA in PBS for 10 minutes, followed by rinsing them twice with ultrapure water. One hundred microliters per well o-cresolphthalein complexone (Sigma-Aldrich) solution at $0.1 \mathrm{mg} / \mathrm{mL}$ was added and incubated for 5 minutes at RT. Afterward, $100 \mu \mathrm{L} 2$-amino2-methyl-3-propanolbuffer (1.5 M, pH 10.8, Sigma-Aldrich) 
with o-cresolphthalein complexone (Sigma-Aldrich) were added per well and incubated for 15 minutes. Finally, $100 \mu \mathrm{L}$ of supernatant was transferred to a new 96-well plate and analyzed at $580 \mathrm{~nm}$ using a fluorescence microplate reader (TECAN).

\section{Statistics}

All experiments were done with cells from three independent donors and with three technical replicates per run. Data are presented by mean \pm SD. To test for significant differences between groups, a one-way or two-way ANOVA followed by Dunnett's or Tukey's multiple comparison post hoc test was performed using GraphPad Prism version 6.00 for Windows. A $P$-value of $\leq 0.01$ was considered significant.

\section{Results}

\section{Nanofibrillar network architecture and physicochemical characterization of PI I-SAP hydrogels}

SEM images of nanofibrillar P11-SAP hydrogels, which were prepared and examined in the study of Koch et al, ${ }^{17}$ were further processed and analyzed with software-supported image analysis to gain more insight into the fibrillar network properties. Prior to the calculation of the different parameters, the images were converted and segmented to black and white pictures as presented in Figure 1. The single-component P11SAPs P11-4 (Figure 1A) and P11-8 (Figure 1B) formed a relatively homogeneous nanofibrillar network structure with a majority of uniform mesh widths. The complementary P11-SAPs P11-13/14 (Figure 1C) and P11-28/29 (Figure 1D) developed more heterogeneous fibrillar networks with an irregular mesh width distribution.

Analysis of the SEM images with the ImageJ plugin DiameterJ was performed to evaluate the following parameters: fiber network porosity (\%), intersection density (number of intersections $/ \mu \mathrm{m}^{2}$ ), and mean fiber diameter (in $\mathrm{nm}$ ) (Table 2). The network porosity of P11-4 and P11-8 was found to be $46 \%$, which is about $14 \%$ higher in relation to the complementary P11-SAPs P11-13/14 and P11-28/29. The network density (ie, the intersection density in number/ $\mu \mathrm{m}^{2}$ ) was almost identical for single-component P11-SAPs, ie, $62.1 / \mu \mathrm{m}^{2}$ for P11-4 and $60.6 / \mu \mathrm{m}^{2}$ for P11-8. For the complementary P11-SAPs P11-28/29, a two-fold higher intersection density was observed with $106.9 \pm 24.5$ number $/ \mu \mathrm{m}^{2}$.
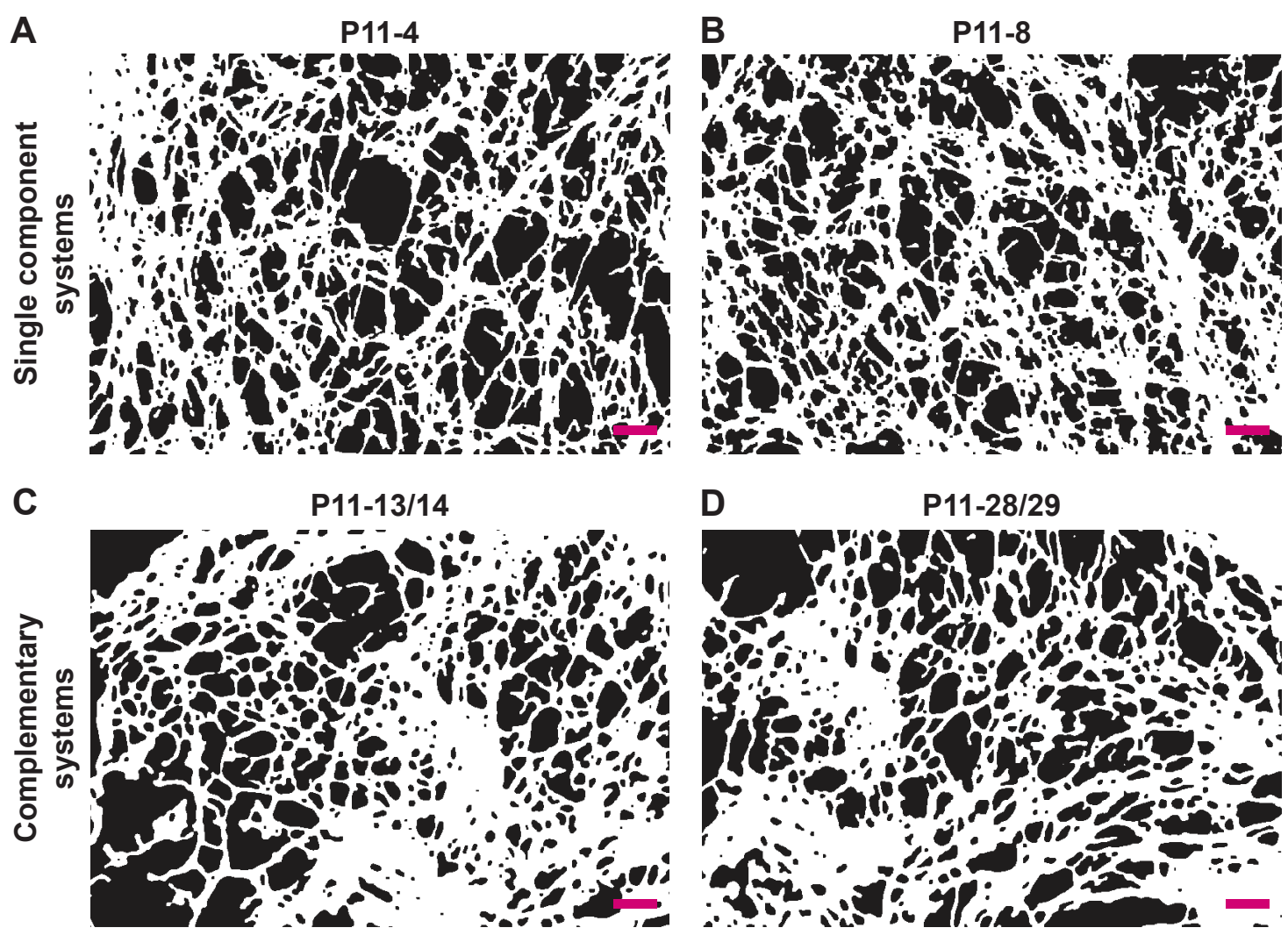

Figure I Processed SEM images of fibrillar PI I-SAP hydrogels.

Note: (A) PI I-4, (B) PI I-8, (C) PI I-I3/ I4, and (D) PI I-28/29 (peptide hydrogels were prepared at I5 mg/mL, scale bar $200 \mathrm{~nm}$, images were converted to black and white pictures).

Abbreviation: SEM, scanning electron microscope. 
Table 2 Analysis of nanofibrillar PI I-SAP hydrogel SEM images

\begin{tabular}{|c|c|c|c|}
\hline & $\begin{array}{l}\text { Fiber } \\
\text { network } \\
\text { porosity (\%) }\end{array}$ & $\begin{array}{l}\text { Intersection } \\
\text { density } \\
\left(\text { number } / \mu \mathrm{m}^{2}\right)\end{array}$ & $\begin{array}{l}\text { Mean fiber } \\
\text { diameter } \\
(\mathrm{nm})\end{array}$ \\
\hline PII-4 & $46 \pm 1.0$ & $62.1 \pm 6.9$ & $41.0 \pm 1.2$ \\
\hline PII-8 & $46 \pm 1.0$ & $60.6 \pm 1.6$ & $40.8 \pm 0.5$ \\
\hline $\mathrm{PII}-13 / 14$ & $3 I \pm 7.0$ & $79.7 \pm 8.6$ & $44.5 \pm 5.2$ \\
\hline PII-28/29 & $34 \pm 5.0$ & $106.9 \pm 24.5$ & $36.8 \pm 2.7$ \\
\hline
\end{tabular}

Note: The parameters "porosity," "intersection density," and "fiber diameter" were assessed by the conversion of SEM images into black and white pictures and further processed and analyzed using Diameter J.

Abbreviation: SEM, scanning electron microscope.

Furthermore, the image analysis identified a relative homogeneous fiber diameter for the single-component P11-SAPs with $41 \pm 1.2 \mathrm{~nm}$ for P11-4 and $40.8 \pm 0.5 \mathrm{~nm}$ for P11-8. The complementary P11-SAPs' fiber diameters showed a higher variability with $44.5 \mathrm{~nm}( \pm 5.2 \mathrm{~nm})$ for P11-13/14 and 36.8 $\mathrm{nm}( \pm 2.7 \mathrm{~nm})$ for P11-28/29.

The P11-SAP hydrogels were further analyzed regarding the physicochemical characteristics of surface charge and swelling ratio (Figure 2). To determine the surface charge, zeta potential measurements were performed as a function of $\mathrm{pH}$ (Figure 2A). At pH 3, all P11-SAPs revealed a positive zeta potential, whereas at $\mathrm{pH} 12$ all P11-SAPs displayed a negative zeta potential. At $\mathrm{pH} \mathrm{7,} \mathrm{P11-SAPs} \mathrm{with} \mathrm{a} \mathrm{nega-}$ tive surface "-2"-net charge (P11-4; P11-13/14) showed a negative zeta potential, whereas a positive zeta potential for P11-SAPs with a “+2"-net charge (P11-8; P11-28/29) was determined.

The theoretically calculated surface net charges (at $\mathrm{pH} 7$ ) of the P11-SAPs were "-2" for P11-4 and P11-13/14 and " +2 " for P11-8 and P11-28/29 (Table 1). Thus, the measured zeta potentials were clearly different from the calculated values. For example, P11-4 and P11-13/14 both have a calculated surface " -2 "-net charge at $\mathrm{pH} 7$ but a zeta potential difference by a factor of 1.5 . Similarly, P11-8 and P11-28/29, with a " +2 "-surface net charge, revealed a positive zeta potential, although it varied by a factor of 3 .

Based on the hydrophilic nature of the tested P11-SAPs hydrogels, they are supposed to retain large amounts of water in their three-dimensional structure. Therefore, swelling ratios were measured at the equilibrium state after 24 hours in PBS (Figure 2B). Swelling ratios for the single-component P11-SAP hydrogels were found to be higher compared with the complementary P11-SAP hydrogels, ie, for P11-4 and P11-8, a swelling ratio of $37.8 \% \pm 1.3 \%$ and $43.8 \% \pm 4.7 \%$ was measured, respectively. In contrast, the complementary P11SAP hydrogels P11-13/14 and P11-28/29 resulted in swelling ratios of $30.0 \% \pm 0.6 \%$ and $26.4 \% \pm 3.4 \%$, respectively.

\section{Impact on cellular reactions \\ Cytocompatibility}

Initially, the cytocompatibility of the disassembled, monomeric P11-SAPs dissolved in cell culture medium was analyzed in different concentrations on HPDLF (Figure 3A) and HCO by measuring the metabolic activity after 24-hour incubation by a resazurin-based, redox-sensitive assay. The incubation of P11-SAP monomers, prepared at $1 \mathrm{mg} / \mathrm{mL}$ and $5 \mathrm{mg} / \mathrm{mL}$ in cell culture medium, showed only minor effects on the metabolic activity of HPDLF. At higher concentrations $(5 \mathrm{mg} / \mathrm{mL})$, P11-13 and P11-28 induced a slight but statistically significant decrease of the metabolic activity of about $15 \%$. The metabolic activity of the osteoblasts showed a similar trend without statistically significant differences (Figure S1A). Furthermore, the cytocompatibility of the different P11-SAPs
A

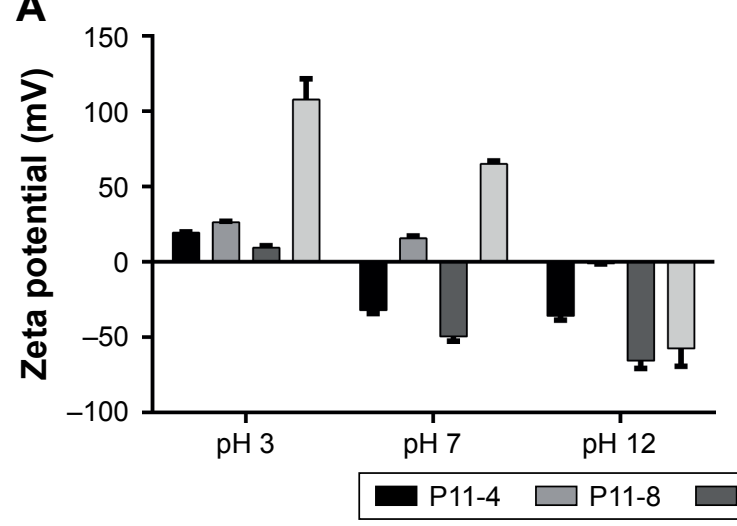

B

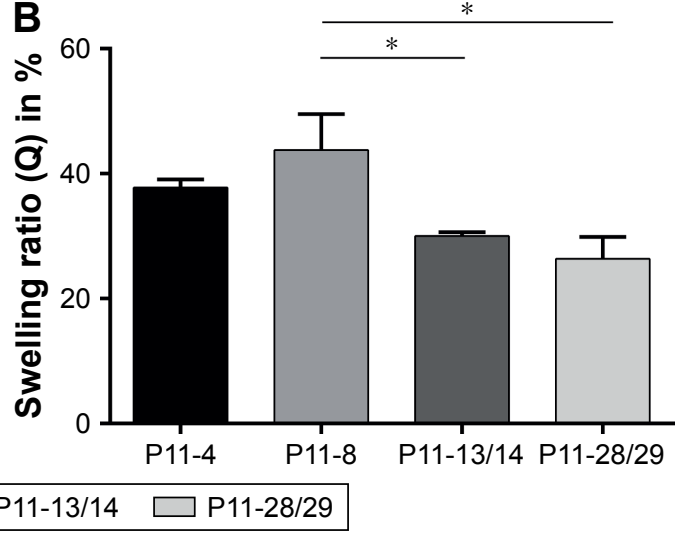

Figure 2 Analysis of surface charge and swelling ratio of the PII-SAPs.

Notes: (A) Surface charge, measured by zeta potential, was determined as a function of $\mathrm{pH}$ for PI I-SAPs in monomeric and fibrillar state (PI I-SAP concentration of $3.0 \mathrm{mg} / \mathrm{mL}$, $\mathrm{n}=3$, measured at $\mathrm{pH} 3,7$, and I2). (B) Swelling ratios measured after 24-hour incubation in PBS (PII -SAP concentration of I5 mg/mL, $\mathrm{n}=3, * P \leq 0.0 \mathrm{I}$ ).

Abbreviation: PII-SAP, II-amino acid self-assembling peptides. 


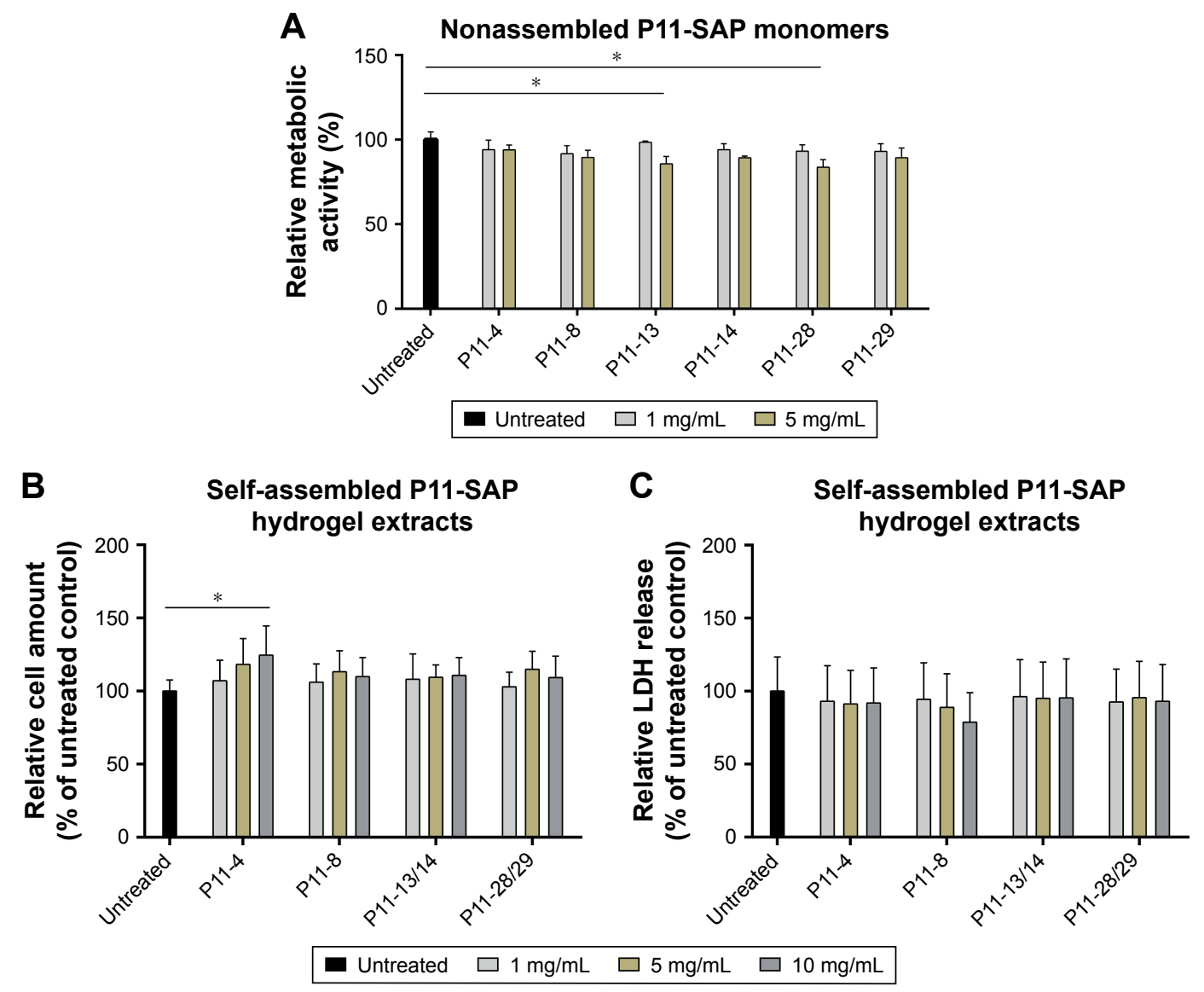

Figure 3 Testing cytocompatibility of monomeric PII-SAP solution and extracts of PII-SAP hydrogels in HPDLF.

Notes: (A) Metabolic activity of HPDLF exposed for 24 hours with the PII-SAP monomers (concentrations: I and 5 mg/mL, PrestoBlue ${ }^{\circledR}$ Cell Viability Reagent, in percent compared with untreated control, $n=3, * P \leq 0.0$ I). (B) Cell amount of HPDLF cells exposed to extraction products of different PII-SAP hydrogels (after 24 hours, I, 5 , and $10 \mathrm{mg} / \mathrm{mL}$, in percent compared with untreated control, $n=3, * P \leq 0.01$, determined by crystal violet staining) and (C) LDH release of HPDLF cells exposed to extraction products of PI I-SAP hydrogels (after 24 hours, I, 5, and $10 \mathrm{mg} / \mathrm{mL}$, in percent compared with untreated control, $\mathrm{n}=3$, $* P \leq 0.0 \mathrm{I}$, measured with LDH cytotoxicity test kit). Abbreviations: HPDLF, human periodontal ligament fibroblast; LDH, lactate dehydrogenase; PI I-SAP, I I-amino acid self-assembling peptide.

was investigated for the self-assembled state (ie, as hydrogels) (Figure 3B and C). For this purpose, extracts of the P11SAP hydrogels were obtained in cell culture medium and HPDLF and HCO were exposed for 24 hours with extracts prepared at 1,5 , and $10 \mathrm{mg} / \mathrm{mL}$ and then analyzed for the cell number and cytotoxicity. The extracts did not affect the cell number except for the extracts of the P11-SAP hydrogel P11-4 (10 mg/mL), which showed a slight but statistically significant increase of HPDLF cell numbers to $124.6 \% \pm 19.9 \%$ (Figure 3B); in $\mathrm{HCO}$, no significant differences were detectable (Figure S1B). To investigate the potential of highly charged P11-SAP hydrogels to interact with and to disrupt cell membranes, an LDH cytotoxicity assay was performed. Cytotoxicity of the P11-SAP hydrogel extracts was examined indirectly by the quantification of the $\mathrm{LDH}$ release of HPDLF and HCO after the extract exposure. There was no deviation identified in comparison with the untreated control (Figures 3C and S1C).

\section{Cell morphology on SAP hydrogels}

Furthermore, the cells were brought into direct contact with the four P11-SAP hydrogels. P11-SAP concentrations of $15 \mathrm{mg} / \mathrm{mL}$ for P11-4 and P11-8 and $10 \mathrm{mg} / \mathrm{mL}$ for P1113/14 and P11-28/29 were chosen for stability and handling reasons. The cell phenotypes were analyzed by actin cytoskeleton staining with phalloidin-TRITC (tetramethylrhodamine), 24 hours after seeding HPDLF and HCO onto P11-SAP hydrogels in the presence of $10 \%$ calf serum in cell culture medium. Nuclear staining could not be executed, as P11-SAP hydrogels possess highly intrinsic autofluorescence (Figure S2). Cells cultured on the control surface (cell culture-adequate SPL glass slides) displayed a spindleshaped, spread phenotype with long actin fibers. The growth of HPDLF and HCO on P11-4 and P11-8 hydrogels resulted in spindle-shaped, outspread cell phenotypes (Figure 4A). In contrast, HPDLF and HCO in contact with P11-13/14 hydrogels developed a roundish, nonspread phenotype. 

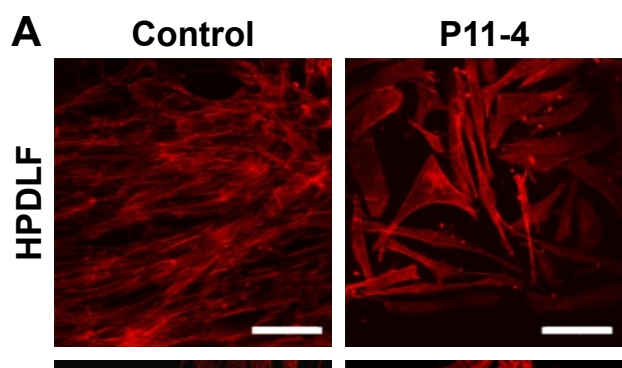
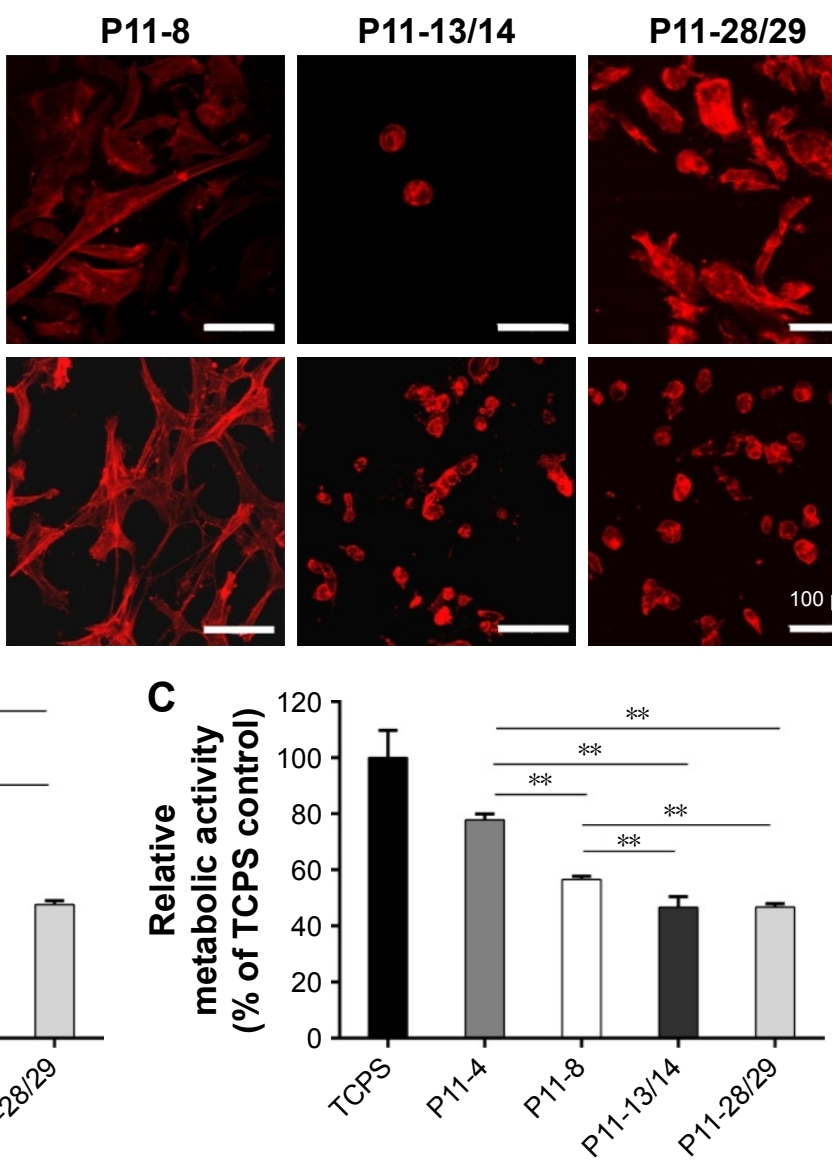

Figure 4 Cellular phenotype and metabolic activity of HPDLF and HCO on PII-SAP hydrogels in the presence of bovine serum (I0\%).

Notes: (A) Fluorescent depiction of the actin cytoskeleton in HPDLF and HCO (after 24 hours, scale bar 100 $\mu \mathrm{m}, \mathrm{n}=6$ ). (B) Metabolic activity of HPDLF and (C) HCO (PrestoBlue ${ }^{\circledR}$ assay performed after 24 hours, \% to TCPS control, $n=3, * * P \leq 0.00$ I).

Abbreviations: HCO, human calvarial osteoblasts; HPDLF, human periodontal ligament fibroblast; PII-SAP, II-amino acid self-assembling peptide; TCPS, tissue culture polystyrene.

The phenotype of HPDLF on P11-28/29 was more heterogeneous with parallel existing roundish and spindle-shaped cells. HCO grown on P11-28/29 hydrogels developed only roundish, nonspread phenotypes (Figure 4A).

The overall metabolic activity of the attached HPDLF and HCO population was quantified at the same time ( 24 hours after seeding). In both cell types, the overall metabolic activity was found to be lower on all P11-SAP hydrogels compared with the control on TCPS. The highest metabolic activity of HPDLF was observed on P11-4 (78.2\% of TCPS control) followed by P11-8 with $66.4 \%$ (Figure 4B). The metabolic activity of HPDLF was even lower on P11-13/14 (38.7\%) and P11-28/29 hydrogels (47.6\%). However, the comparison of the complementary P11-SAP hydrogels revealed that HPDLF metabolic activity was higher on P11-28/29 than on P11-13/14. A similar metabolic activity pattern was shown for $\mathrm{HCO}$, although there was no difference detected between P11-13/14 and P11-28/29 hydrogels (Figure 4C). The reduced overall metabolic activity of the cells in direct contact with the P11-SAP hydrogels implies a lower cell attachment, as in the TCPS control, confirming the optical impression estimated by the microscopic phenotype analysis.

\section{Fibronectin adsorption to SAP hydrogels}

The phenotype of cells in contact with P11-SAP hydrogels was also tested under serum-free conditions and in the presence of fibronectin. HPDLF and HCO phenotypes were not spread in contact with P11-SAP hydrogels under serum-free and noncoating conditions. The precoating of P11-SAP hydrogels with fibronectin $(300 \mu \mathrm{g} / \mathrm{mL})$ prior to cell seeding induced outspread, spindle-shaped HPDLF with long actin fibers (Figure 5A) on P11-4, P11-8, and P11-28/29 hydrogels. Only on P11-13/14 hydrogels did the cells not spread at all. Seeding of HCO on fibronectin-coated surface resulted in a roundish, nonspread phenotype on P11-13/14 and P11-28/29 (Figure S3). To attain a deeper understanding of the varying cellular reactions after fibronectin coating, 

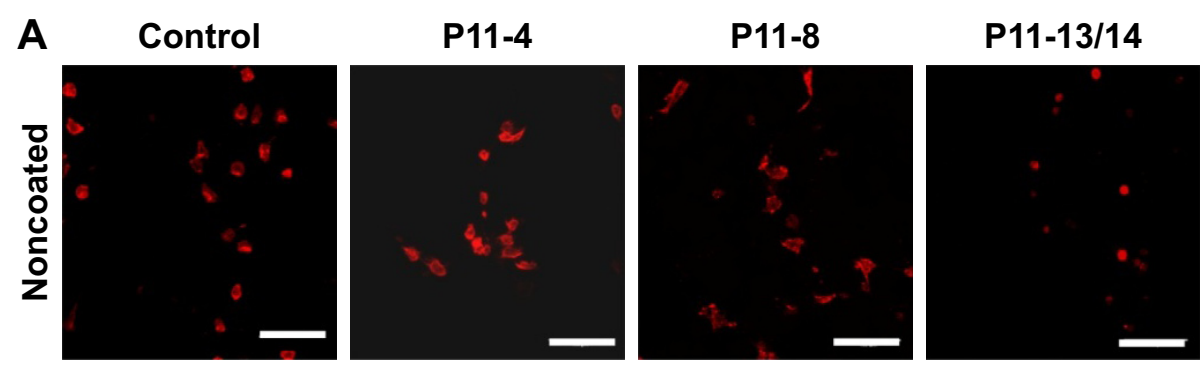

P11-28/29

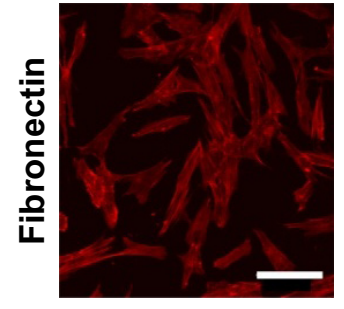

B

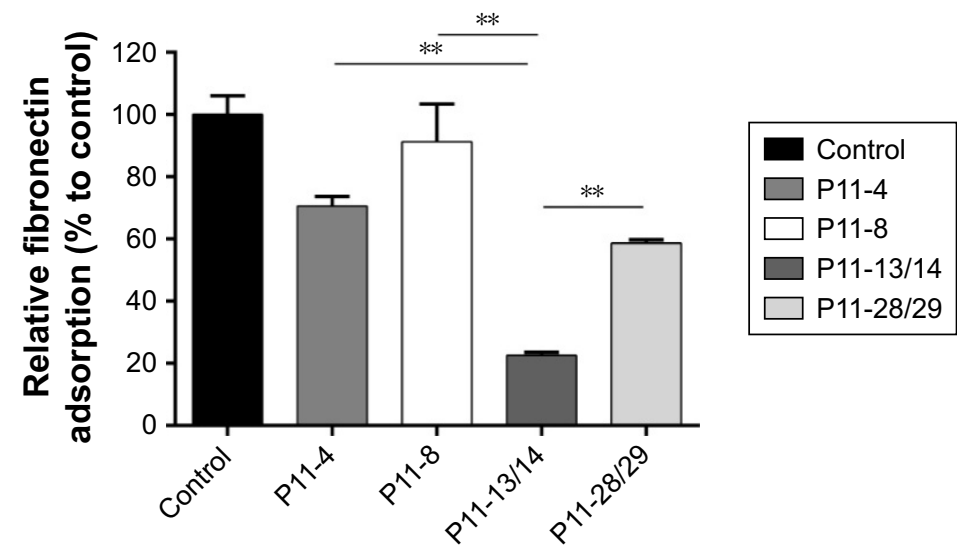

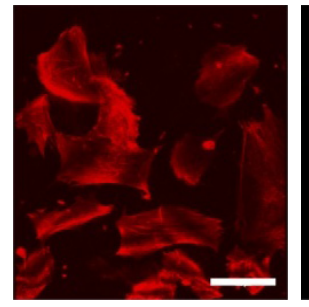

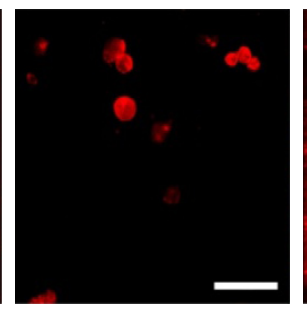

C
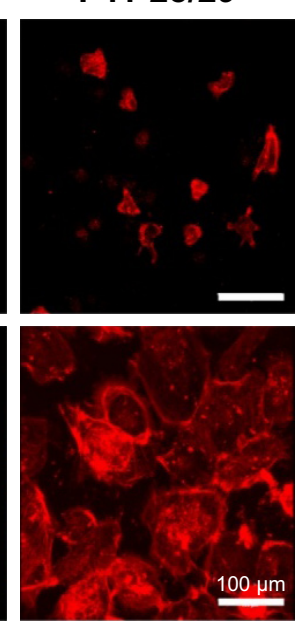

Fibronectin
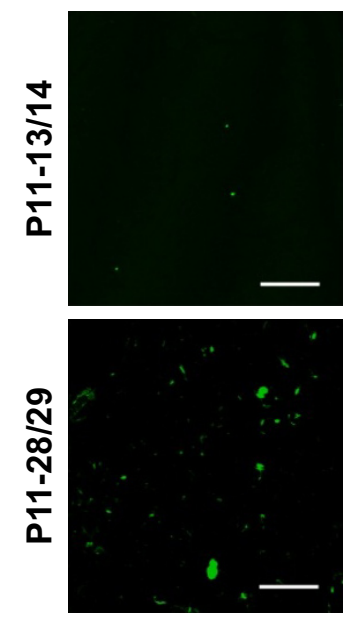

Figure 5 Fibronectin coating of PII-SAP hydrogels.

Notes: (A) Fluorescent depiction of the actin cytoskeleton of HPDLF cultured for 24 hours on PI I-SAP hydrogels under noncoated/serum-free conditions or precoated with fibronectin (confocal microscopy, fibronectin concentration $300 \mu \mathrm{g} / \mathrm{mL}$, scale bar $100 \mu \mathrm{m}$ ). (B) Quantification of fibronectin adsorption on PII-SAP hydrogels after I-hour incubation with fibronectin-supplemented PBS $(300 \mu \mathrm{g} / \mathrm{mL}, \mathrm{n}=3, * * \mathrm{P} \leq 0.00 \mathrm{I})$. (C) Immunostaining of bound fibronectin on PII-I3/I4 and PII-28/29 hydrogels (confocal microscopy, scale bar $100 \mu \mathrm{m}$ ).

Abbreviations: HPDLF, human periodontal ligament fibroblast; PI I-SAP, I I-amino acid self-assembling peptide.

we analyzed the fibronectin adsorption after 1 hour of incubation on P11-SAP hydrogels (Figure 5B). Protein adsorption on TCPS surfaces was taken as a control and set to $100 \%$. Fibronectin adsorption was highest on the single-component systems P11-8 (91.2\%) and P11-4 (58.9\%) compared with the complementary P11-SAP hydrogels P11-28/29 at 58.9\% and P11-13/14 at 22.5\%. Moreover, the immunofluorescent, microscopic analysis of fibronectin adsorption confirmed the higher adsorption degree on P11-28/29 hydrogels compared with P11-13/14 hydrogels (Figure 5C).

To evaluate whether the cellular phenotype was affected by the P11-SAP hydrogel stiffness, different P11-SAP concentrations were tested. The adjusted hydrogel stiffnesses, obtained by changing the peptide concentration from 10 to $5 \mathrm{mg} / \mathrm{mL}$, was $\mathrm{G}^{\prime}=6.8$ and $1.0 \mathrm{kPa}$ for $\mathrm{P} 11-13 / 14$ and $\mathrm{G}^{\prime}=1.2$ and $0.4 \mathrm{kPa}$ for P11-28/29 (Figure 6A). For both complementary P11-SAP hydrogels P11-13/14 and P11-28/29, the lower peptide concentrations and thus induced lower stiffnesses impaired cell spreading, resulting in roundish cells. Thus, different hydrogel stiffness could not change the cellular phenotypes toward a spread morphology (Figure 6B). Hence, neither protein adsorption (Figure 5) nor peptide concentration and thus hydrogel stiffness (Figure 6) led to a change of HCO phenotype on P11-13/14 and P11-28/29 hydrogels after 24 hours.

\section{Osteogenic differentiation on SAP hydrogels}

Finally, we investigated the capacity of P11-SAP hydrogels regarding the growth and osteogenic differentiation of $\mathrm{HCO}$ in long-term experiments. For this purpose, HCOs were 
A

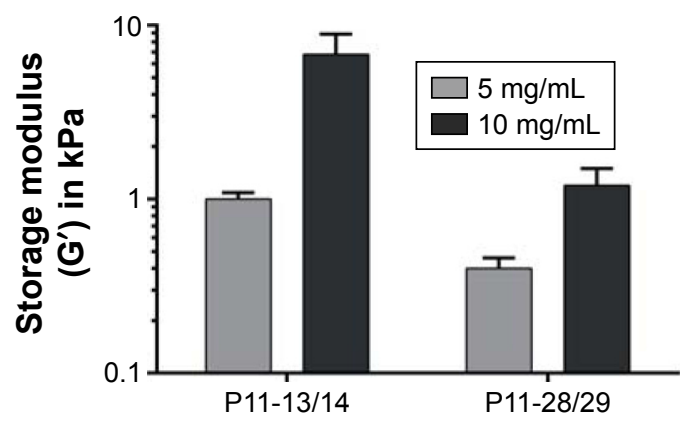

B

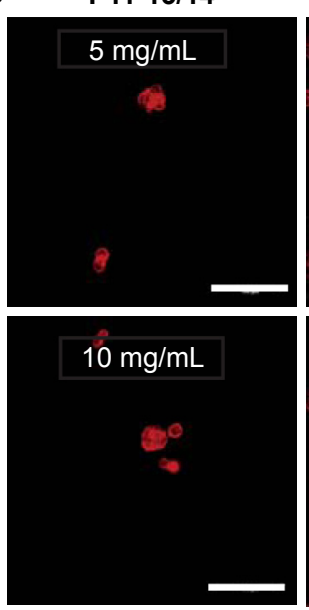

P11-28/29

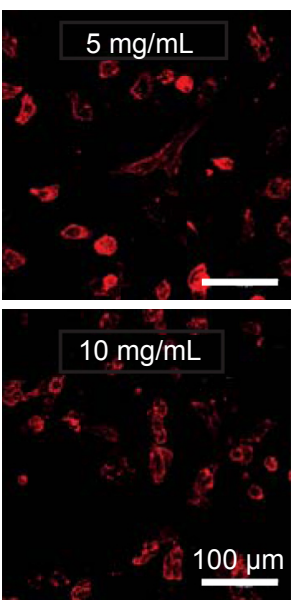

Figure 6 Hydrogel stiffness and phenotype of $\mathrm{HCO}$ in contact with PI I-SAP hydrogels of different concentrations.

Notes: (A) Hydrogel stiffness displayed as storage modulus of PII-I3/I4 and PII-28/29 hydrogels (at 5 and I0 mg/mL). (B) HCO phenotypes were assessed on PI I-I3/I4 and PI I-28/29 hydrogels ( 5 and $10 \mathrm{mg} / \mathrm{mL}$, after 24 hours) by staining the actin cytoskeleton (scale bar $100 \mu \mathrm{m}$ ).

Abbreviations: HCO, human calvarial osteoblasts; PI I-SAP, I I-amino acid self-assembling peptide.

cultivated for up to 30 days and the metabolic activity was analyzed as an indirect measure for the development of the cell number over time. Metabolic activity of the TCPS control on day 1 was taken as $100 \%$. The highest metabolic activity (189.3\%) and thus an indication for the highest cell number were found after 14 days of cultivation of HCO on P11-4 hydrogels (Figure 7A). HCO cultivation on the complementary P11-SAP hydrogels, P11-13/14 and P11-28/29 resulted in metabolic activity rates of $31.7 \%$ and $16.7 \%$, respectively, indicating low cell numbers. Long-term cultivation of HPDLF on P11-SAP hydrogels (data not shown) revealed high metabolic activity rates for P11-4 (182.4\%) and P11-8 (145.5\%) after 14 days.

Because the P11-4 and P11-8 hydrogels allowed the highest rates of cell adhesion and cell amount, we selected them for further osteogenic differentiation experiments with HCO. To this end, we quantified ALP activity as a marker for osteogenic differentiation (Figure 7B). ALP activity after 7 and 14 days was increased in HCO cultured on TCPS. However, HCO in contact with P11-4 and P11-8 hydrogels showed significantly increased ALP activity after 7 and 14 days cultivation compared with the TCPS control. ALP activity was found to be three times higher for P11-4 after 14 days and four times higher for P11-8 compared with TCPS control surfaces. Moreover, ALP activity at day 14 was significantly higher (by a factor of 1.5) on P11-8 than on P11-4 hydrogels.

The osteogenic marker OPG was analyzed after osteogenic stimulation of HCO on TCPS and P11-SAP hydrogels (Figure 7C). A significantly higher OPG concentration was measured for HCO cultured for 14 days on TCPS compared with P11-4 and P11-8 hydrogels. For P11-SAP hydrogels, OPG levels in cell lysates were found to be significantly higher on P11-8 than on P11-4 hydrogels. As a further marker for osteogenic differentiation, extracellular calcium deposition was measured after 30 days in $\mathrm{HCO}$ under osteogenic stimulation (Figure 7D). Already after 1 day, significant calcium amounts were detectable on P11-4 and P11-8 hydrogels. Moreover, calcium deposition was found to be significantly higher (factor of 1.4) after 30 days of incubation on P11-4 and P11-8 hydrogels compared with HCO grown on TCPS.

\section{Discussion}

In the present study, we analyzed four $\beta$-sheet forming P11SAP hydrogels (P11-4, P11-8, P11-13/14, and P11-28/29) regarding their physicochemical properties and capacities to act as scaffolds for periodontal therapy by means of in vitro testing with cells involved in periodontal tissue regeneration.

As SAPs can be rationally designed to yield tailored hydrogel stiffness and meet specific tissue elasticities, they are promising materials in biomedical applications, eg, for periodontal therapy. ${ }^{28}$ SAPs are shown to have compatible fiber diameters similar to extracellular matrix (ECM) molecules. ${ }^{12,29}$ In previous studies, it was demonstrated that each individual SAP composition will affect the hydrogel characteristics regarding fiber morphology, surface charge, and stiffness. Therefore, we analyzed the nanofibrillar architecture, surface charge, and swelling ratio of the four P11SAP hydrogels. The mean fibril diameters of all assembled nanofibrillar P11-SAP hydrogels (36.8-44.5 nm) were found to be in a range similar to that reported for the naturally 
A

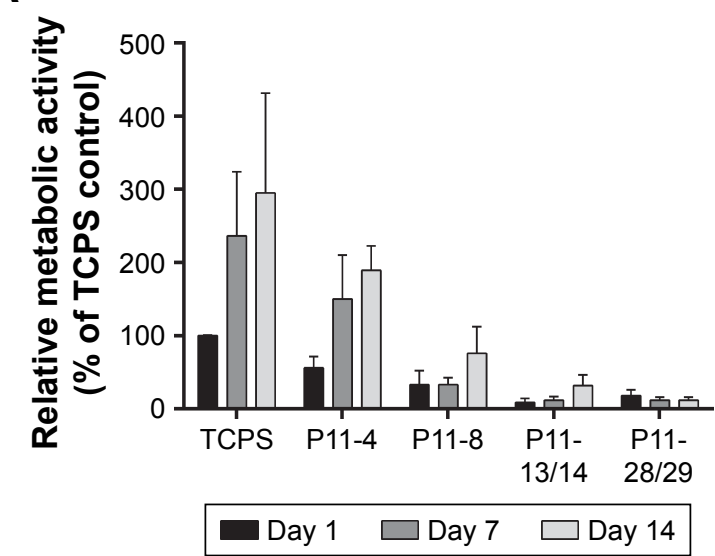

C

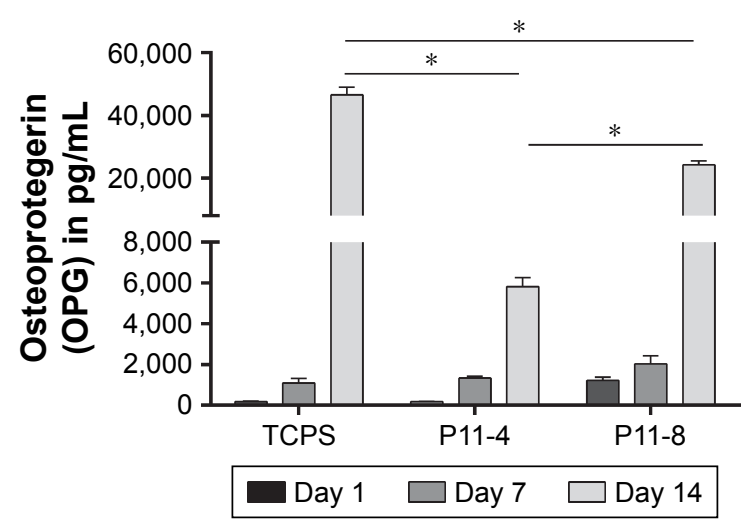

B

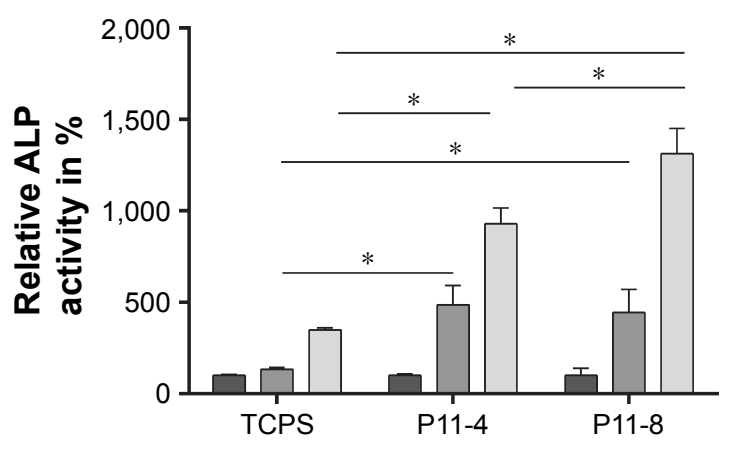

$\square$ Day $1 \square$ Day $7 \square$ Day 14

D

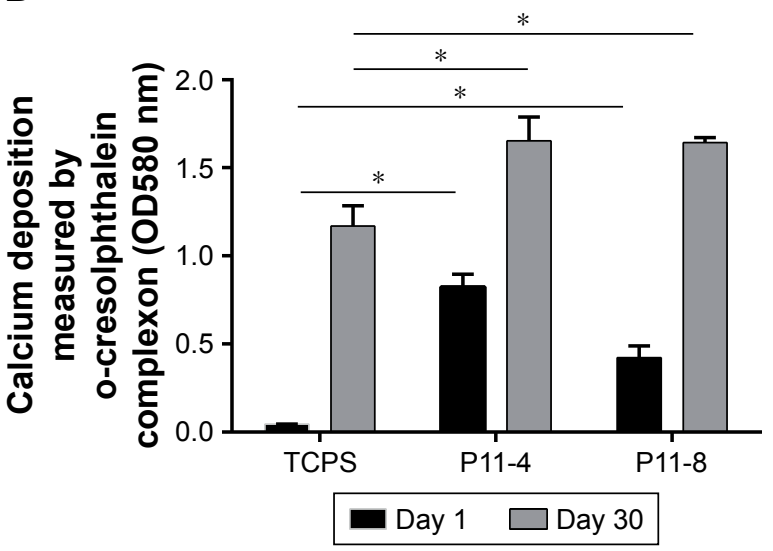

Figure 7 Analysis of metabolic activity and osteogenic differentiation capacities of HCO on PII-SAP hydrogels in long-term culture.

Notes: (A) Metabolic activity of HCO on TCPS or PI I-4/PI I-8 hydrogels (assessed after I, 7, and I4 days by PrestoBlue ${ }^{\circledR}$ assay, \% of TCPS control on day I, n=3, I5 mg/mL peptide concentration). (B) ALP activity (\% of TCPS control on day I, assessed on days I, 7 and I4, n=3), (C) amount of OPG on days I, 7, and I4 ( $=3$ ), (D) calcium deposition (measured on days I and 30 ) (all data were normalized to metabolic activity, ${ }^{*} P \leq 0.0 \mathrm{I}$ ).

Abbreviations: HCO, human calvarial osteoblasts; PI I-SAP, I I-amino acid self-assembling peptide; TCPS, tissue culture polystyrene.

occurring ECM proteins, ie, collagen fibrils in the range of $30-300 \mathrm{~nm}$ in diameter ${ }^{30}$ or fibrillin, which forms microfibrils of about $10 \mathrm{~nm} .^{31}$

In our analyses, the nanofibrillar network architecture of the single-component systems (P11-4, P11-8) was found to be different compared with the two-component P11-SAP systems (P11-13/14, P11-28/29) regarding their intersection density and pore size. The discrepancy between the two P11-SAP systems cannot be explained directly by different hydrogel stiffnesses because the hydrogels with the higher intersection density had lower hydrogel stiffness, as was analyzed in a previous study. ${ }^{17}$ Because, for example, the P11-28/29 hydrogels revealed the highest intersection density but lowest hydrogel stiffness, we conclude that the individual fiber strength affects the final hydrogel stiffness of the P11-SAP systems rather than the intersection density due to a denser packaging of a fibril. This phenomenon has also been described in a previous study that investigated the effect of increased ionic strength on the elastic modulus of peptide hydrogels. ${ }^{32}$

It is known that hydrogel stiffness can influence cellular responses, and thus, it is a crucial parameter to address a tissue regeneration purpose. ${ }^{4,5}$ Engler et $\mathrm{al}^{33}$ showed that nondifferentiated MSC specify lineage and commit to phenotypes with extreme sensitivity to the corresponding tissue-level elasticity. They could show that very soft matrices mimicking brain tissue induced neurogenic differentiation, whereas stiffer matrices induced myogenic differentiation and comparatively rigid matrices induced osteogenic differentiation. The mechanical properties of tissue niches vary from $0.1 \mathrm{kPa}$ of soft brain tissue to $>30 \mathrm{kPa}$ of rigid calcifying bone. The hydrogel stiffness of the four P11-SAP systems was reported by Koch et $\mathrm{al}^{17}$ to be in the range of $1.7-31.5 \mathrm{kPa}$ and thus matches soft to hard tissue elasticities.

One prerequisite for the application of a biomaterial is its cytocompatibility. The cytocompatibility of the four 
selected P11-SAPs was tested in vitro in human fibroblasts and osteoblasts of the periodont because these cell types are essential for the periodontal regeneration process. The P11-SAP monomers as well as P11-SAP hydrogel extracts cultured with HPDLF and HCO did not show cytotoxic reactions and can thus be classified as cytocompatible. The slight reduction of the metabolic activity for HPDLF induced by P11-13 and P11-28 monomers at high monomer concentrations $(5 \mathrm{mg} / \mathrm{mL})$ might be explained by the release of the counterions of P11-13 (78.5\%; ammonium salt) and P11-28 (70.7\%; TFA). TFA has been shown to impair the proliferation of L929 fibroblasts. ${ }^{23}$ Previous reports have already shown the biocompatibility of P11-SAP hydrogels on human dermal fibroblasts and murine cells. ${ }^{11,34}$

The process of periodontal regeneration induced by implanted or injected biomaterials is highly complex and involves several characteristic events such as cell proliferation, migration differentiation, and tissue maturation. ${ }^{35}$ An early step in the cascade of tissue regeneration after the implantation of a biomaterial is the adhesion of cells to the biomaterial. ${ }^{5}$ The cell adhesion characteristics influence the capacity of the cells to proliferate and differentiate. The cellular phenotype is known to be controlled by the adsorption of soluble proteins from blood or the surrounding wound fluid and is closely related to the biomaterials topography, chemistry, or surface charge. ${ }^{36}$ Fibronectin is a major component of the ECM that regulates cell adhesion and ECM interactions. ${ }^{37,38}$ Furthermore, fibronectin binds to a variety of different artificial materials and can potentially influence cellular responses rather than the material surface itself. ${ }^{38,39}$ Thus, we decided to investigate the effect of fibronectin adsorption on P11-SAP hydrogels and subsequently on the cellular phenotype.

In previous studies, it has already been shown that fibronectin adsorbs rather on a hydrophobic than on hydrophilic surfaces. ${ }^{40,41}$ The isoelectric point of fibronectin is about 5.5-6.3 and is thus negatively charged under physiological conditions. ${ }^{42,43}$ As fibronectin consists of acidic as well as of basic surface residues, it can bind to positively or negatively charged biomaterials, but with different protein conformation. ${ }^{44,45}$ In the present study, fibronectin bound to all P11-SAP hydrogels tested, but preferably to P11-4 and P11-8. As all four P11-SAP systems contain several polar amino acid residues (ie, Gln, Glu, Orn), they display similar hydrophilic surfaces. Although the theoretical calculated net surface charges $(+2 /-2)$ are similar for all P11-SAPs tested, their surface charge measured by zeta potential was different for positive (P11-8, P11-28/29) and negative (P11-4,
P11-13/14) P11-SAP fibrils. Thus, the reduced fibronectin adsorption on P11-13/14 hydrogels can be explained by the high zeta potential of P11-13/14 fibrils $(-49.5 \pm 2.5 \mathrm{mV})$ compared with P11-4 (-31.9 $\pm 1.8 \mathrm{mV})$, resulting in a higher repulsion of fibronectin and thus lower protein adsorption. Similar effects were reported by Cai et $\mathrm{al}^{46}$ in their study of fibrinogen binding on titanium films displaying $\mathrm{COOH}$ functional surface groups. These authors observed that a lower zeta potential of a substrate leads to higher charge repulsion and thus lower fibrinogen adsorption.

The adsorption of fibronectin to four P11-SAP hydrogels was found to be reflected by variable cell adhesion characteristics and morphologic appearance of both cell types tested. HPDLF was extensively spread on the hydrogels with the high fibronectin adsorption properties (P11-4 and P11-8 hydrogels), whereas the cells were not spread on hydrogels with low fibronectin adsorption, such as on P11-13/14 hydrogels. Similar effects were shown for cellular spreading in the presence of FBS. Because cell adhesion and spreading are important in the first phase of tissue-biomaterial interaction after implantation in vivo, and because cell adhesion and spreading depends on the protein-binding capacity of a material, we assumed that P11-4 and P11-8 hydrogels are the most suitable candidates to study long-term cultivation and cellular differentiation.

Cell proliferation is another key parameter in the process of tissue regeneration. ${ }^{47}$ We could show that the amounts of HPDLF and HCO on P11-SAP hydrogels were highest on P11-4 and P11-8. Because these hydrogels also showed high fibronectin adsorption, we assumed a direct connection between high fibronectin adsorption, initial cell adhesion, and high proliferation rates. Based on these results, P11-4 and P11-8 hydrogels were again chosen as the best candidates for the differentiation study with HCO.

Periodontal regeneration of the alveolar bone or the periodontal cementum is accompanied by hard tissue formation, ie, bone and cementum. To evaluate the osteogenic potential of P11-4 and P11-8 hydrogels, we induced HCO for osteogenic differentiation in contact with the hydrogels. $\mathrm{HCO}$ differentiation was measured by ALP activity, OPG expression, and calcium amount of the ECM. After 14 days of culture, ALP activity and OPG were significantly increased on P11-8 hydrogels compared with P11-4 hydrogels. The high osteogenic differentiation potential of P11-8 hydrogels might be based on its surface chemistry. P11-8 contains three positively charged ornithines, whereas P11-4 contains three negatively charged glutamic acids. It was already shown in the study of Griffin et $\mathrm{al}^{7}$ that adipose-derived mesenchymal 
stem cells can react to modifications of plasma-modified scaffolds using $\mathrm{NH}_{2}$ and $\mathrm{COOH}$ residues by changes in ALP activity and osteogenic gene expressions. Thus, our results are in good alignment to the study of Griffin et al, ${ }^{7}$ demonstrating a higher osteogenic differentiation potential on $\mathrm{NH}_{2}$ than on $\mathrm{COOH}$-modified surfaces. The initial degree of calcium deposition after 1 day of culture was distinctly higher on P11-4 compared with P11-8 hydrogels. This difference in initial calcium deposition may be explained by the diverging peptide sequences of $\mathrm{P} 11-4$ and $\mathrm{P} 11-8$, resulting in either a negative or a positive surface charge. As described previously by Thomson et al, ${ }^{48}$ the calcium-binding site of the SAP is made up of four central glutamic acid residues (two from each strand). Due to the negatively charged surface of P11-4 by glutamic acid residues, the binding of the divalent calcium ions causes a high mineral deposition. In contrast, the peptide sequence of P11-8 contains ornithine residues that lead to an overall positive surface charge, which cannot bind the positive calcium ions. However, after 30 days of culture, calcium deposition on P11-4 and P11-8 hydrogels no longer differed. Thus, the mineralization deposited by the cells seemed to have a greater effect in the long run than the mineralization due to the hydrogels' surface charge.

In summary, the present study demonstrates that the four different P11-SAP hydrogels tested possess specific physicochemical characteristics that lead to variations in protein adsorption and thus to different cellular reactions. Based on the present study, P11-SAP hydrogels, especially P11-4 and P11-8, are suitable candidates as scaffolds in periodontal therapy, as they provide ECM-mimetic fibrillar architecture and favorable cellular reactions regarding the proliferation and osteogenic differentiation of important periodontal cells.

\section{Conclusion}

In this study, we demonstrated that the single-component P11-SAP systems P11-4 and P11-8 have suitable and adjustable nanofibrillar architectural and physicochemical properties that enable HPDLF and HCO cell adhesion, growth, and differentiation, which might be suitable for soft-to-hard tissue formation in regenerative periodontal therapy. Thus, these peptides should be further investigated regarding their in vivo potential, eg, as drug delivery systems for the application of antimicrobial agents in a microbial-rich environment like the periodontal pocket.

\section{Acknowledgments}

The authors would like to thank Michael Hug and Dominik Lysek (credentis AG) for funding and supporting this work and for the valuable discussions.

\section{Disclosure}

The authors report no conflicts of interest in this work.

\section{References}

1. Grzesik WJ, Narayanan AS. Cementum and periodontal wound healing and regeneration. Crit Rev Oral Biol Med. 2002;13(6):474-484.

2. Kim J, Amar S. Periodontal disease and systemic conditions: a bidirectional relationship. Odontology. 2006;94(1):10-21.

3. Wang HL, Cooke J. Periodontal regeneration techniques for treatment of periodontal diseases. Dent Clin North Am. 2005;49(3):637-659.

4. Thevenot $\mathrm{P}, \mathrm{Hu} \mathrm{W}$, Tang L. Surface chemistry influences implant biocompatibility. Curr Top Med Chem. 2008;8(4):270-280.

5. Anselme K. Osteoblast adhesion on biomaterials. Biomaterials. 2000; 21(7):667-681.

6. Keselowsky BG, Collard DM, García AJ. Surface chemistry modulates fibronectin conformation and directs integrin binding and specificity to control cell adhesion. J Biomed Mater Res A. 2003;66(2):247-259.

7. Griffin MF, Ibrahim A, Seifalian AM, Butler PEM, Kalaskar DM, Ferretti P. Chemical group-dependent plasma polymerisation preferentially directs adipose stem cell differentiation towards osteogenic or chondrogenic lineages. Acta Biomater. 2017;50:450-461.

8. Ge S, Zhao N, Wang L, et al. Bone repair by periodontal ligament stem cell seeded nanohydroxyapatite-chitosan scaffold. Int J Nanomedicine. 2012;7:5405.

9. Ni P, Fu S, Fan M, et al. Preparation of poly(ethylene glycol)/polylactide hybrid fibrous scaffolds for bone tissue engineering. Int J Nanomedicine. 2011;6:3065.

10. Koutsopoulos S. Self-assembling peptide nanofiber hydrogels in tissue engineering and regenerative medicine: progress, design guidelines, and applications. J Biomed Mater Res A. 2016;104(4):1002-1016.

11. Maude S, Ingham E, Aggeli A. Biomimetic self-assembling peptides as scaffolds for soft tissue engineering. Nanomedicine. 2013;8(5): 823-847.

12. Kumada Y, Zhang S. Significant type I and type III collagen production from human periodontal ligament fibroblasts in 3D peptide scaffolds without extra growth factors. PLoS One. 2010;5(4):e10305.

13. Takeuchi T, Bizenjima $T$, Ishii $Y$, et al. Enhanced healing of surgical periodontal defects in rats following application of a self-assembling peptide nanofibre hydrogel. J Clin Periodontol. 2016;43(3):279-288.

14. Firth A, Aggeli A, Burke JL, Yang X, Kirkham J. Biomimetic selfassembling peptides as injectable scaffolds for hard tissue engineering. Nanomedicine. 2006;1(2):189-199.

15. Kind L, Stevanovic S, Wuttig S, et al. Biomimetic remineralization of carious lesions by self-assembling peptide. J Dent Res. 2017;96(7): 790-797.

16. Kirkham J, Firth A, Vernals D, et al. Self-assembling peptide scaffolds promote enamel remineralization. J Dent Res. 2007;86(5):426-430.

17. Koch F, Müller M, König F, et al. Mechanical characteristics of beta sheet-forming peptide hydrogels are dependent on peptide sequence, concentration and buffer composition. R Soc Open Sci. 2018; 5(3): 171562.

18. Aggeli A, Nyrkova IA, Bell M, et al. Hierarchical self-assembly of chiral rod-like molecules as a model for peptide beta-sheet tapes, ribbons, fibrils, and fibers. Proc Natl Acad Sci U S A. 2001;98(21):11857-11862.

19. Carrick LM, Aggeli A, Boden N, Fisher J, Ingham E, Waigh TA. Effect of ionic strength on the self-assembly, morphology and gelation of $\mathrm{pH}$ responsive $\beta$-sheet tape-forming peptides. Tetrahedron. 2007;63(31):7457-7467.

20. Aggeli A, Bell M, Carrick LM, et al. $\mathrm{pH}$ as a trigger of peptide beta-sheet self-assembly and reversible switching between nematic and isotropic phases. J Am Chem Soc. 2003;125(32):9619-9628.

21. Wilshaw SP, Aggeli A, Fisher J, Ingham E. The biocompatibility and immunogenicity of self-assembling peptides for use in tissue engineering and regenerative application. Tissue Eng Part A. 2008;14(5):785.

22. Kyle S, Felton SH, Mcpherson MJ, Aggeli A, Ingham E. Rational molecular design of complementary self-assembling peptide hydrogels. Adv Healthc Mater. 2012;1(5):640-645. 
23. Maude S, Miles DE, Felton SH, et al. De novo designed positively charged tape-forming peptides: self-assembly and gelation in physiological solutions and their evaluation as 3D matrices for cell growth. Soft Matter. 2011;7(18):8085.

24. Bell CJ, Carrick LM, Katta J, et al. Self-assembling peptides as injectable lubricants for osteoarthritis. J Biomed Mater Res A. 2006;78(2): 236-246.

25. Kyle S, Felton SH, Mcpherson MJ, Aggeli A, Ingham E. Rational molecular design of complementary self-assembling peptide hydrogels. Adv Healthc Mater. 2012;1(5):640-645.

26. Hotaling NA, Bharti K, Kriel H, Simon CG. DiameterJ: a validated open source nanofiber diameter measurement tool. Biomaterials. 2015;61:327-338.

27. Park H, Guo X, Temenoff JS, et al. Effect of swelling ratio of injectable hydrogel composites on chondrogenic differentiation of encapsulated rabbit marrow mesenchymal stem cells in vitro. Biomacromolecules. 2009;10(3):541-546

28. Sieminski AL, Was AS, Kim G, Gong H, Kamm RD. The stiffness of three-dimensional ionic self-assembling peptide gels affects the extent of capillary-like network formation. Cell Biochem Biophys. 2007; 49(2):73-83.

29. Cunha C, Panseri S, Villa O, Silva D, Gelain F. 3D culture of adult mouse neural stem cells within functionalized self-assembling peptide scaffolds. Int J Nanomedicine. 2011;6:943.

30. Ushiki T. The three-dimensional ultrastructure of the collagen fibers, reticular fibers and elastic fibers: a review. Kaibogaku Zasshi. 1992; 67(3):186-199.

31. Sakai LY, Keene DR, Engvall E, Fibrillin EE. Fibrillin, a new 350-kD glycoprotein, is a component of extracellular microfibrils. J Cell Biol. 1986;103(6 Pt 1):2499-2509.

32. Feng Y, Taraban M, Yu YB. The effect of ionic strength on the mechanical, structural and transport properties of peptide hydrogels. Soft Matter. 2012;8(46):11723-11731.

33. Engler AJ, Sen S, Sweeney HL, Discher DE. Matrix elasticity directs stem cell lineage specification. Cell. 2006;126(4):677-689.

34. Kyle S, Aggeli A, Ingham E, Mcpherson MJ. Recombinant selfassembling peptides as biomaterials for tissue engineering. Biomaterials. 2010;31(36):9395-9405.

35. Polimeni G, Xiropaidis AV, Wikesjö UM. Biology and principles of periodontal wound healing/regeneration. Periodontol. 2006;41(1):30-47.

36. Castner DG, Ratner BD. Biomedical surface science: foundations to frontiers. Surf Sci. 2002;500(1-3):28-60.
37. Macdonald DE, Markovic B, Boskey AL, Somasundaran P. Physicochemical properties of human plasma fibronectin binding to well characterized titanium dioxide. Colloids Surf B Biointerfaces. 1998;11(3): $131-139$.

38. Guo C, Wu C, Chen M, Zheng T, Chen N, Cummings PT. Molecular modeling of fibronectin adsorption on topographically nanostructured rutile (110) surfaces. Appl Surf Sci. 2016;384:36-44.

39. Wilson CJ, Clegg RE, Leavesley DI, Pearcy MJ. Mediation of biomaterialcell interactions by adsorbed proteins: a review. Tissue Eng. 2005; 11(1-2):1-18.

40. Wu CS, Chen GC. Adsorption of proteins onto glass surfaces and its effect on the intensity of circular dichroism spectra. Anal Biochem. 1989;177(1):178-182.

41. Jönsson U, Ivarsson B, Lundström I, Berghem L. Adsorption behavior of fibronectin on well-characterized silica surfaces. J Colloid Interface Sci. 1982;90(1):148-163.

42. Paul JI, Hynes RO. Multiple fibronectin subunits and their posttranslational modifications. J Biol Chem. 1984;259(21):13477-13487.

43. Vuento M, Wrann M, Ruoslahti E. Similarity of fibronectins isolated from human plasma and spent fibroblast culture medium. FEBS Lett. 1977;82(2):227-231.

44. Richter H, Hörmann H. Early and late cathepsin D-derived fragments of fibronectin containing the C-terminal interchain disulfide cross-link. Hoppe Seylers Z Physiol Chem. 1982;363(4):351-364.

45. Sekiguchi K, Hakomori S. Topological arrangement of four functionally distinct domains in hamster plasma fibronectin: a study with combination of S-cyanylation and limited proteolysis. Biochemistry. $1983 ; 22(6): 1415-1422$.

46. Cai K, Frant M, Bossert J, Hildebrand G, Liefeith K, Jandt KD. Surface functionalized titanium thin films: zeta-potential, protein adsorption and cell proliferation. Colloids Surf B Biointerfaces. 2006;50(1):1-8.

47. Ghasemi-Mobarakeh L, Prabhakaran MP, Tian L, ShamirzaeiJeshvaghani E, Dehghani L, Ramakrishna S. Structural properties of scaffolds: crucial parameters towards stem cells differentiation. World J Stem Cells. 2015;7(4):728.

48. Thomson BM,HardakerL, Davies RPW, etal.P11-15(NNRFEWEFENN): a biocompatible, self-assembling peptide with potential to promote enamel remineralisation. Abstract 47. Caries Res. 2014;48(411):405. 


\section{Supplementary materials}

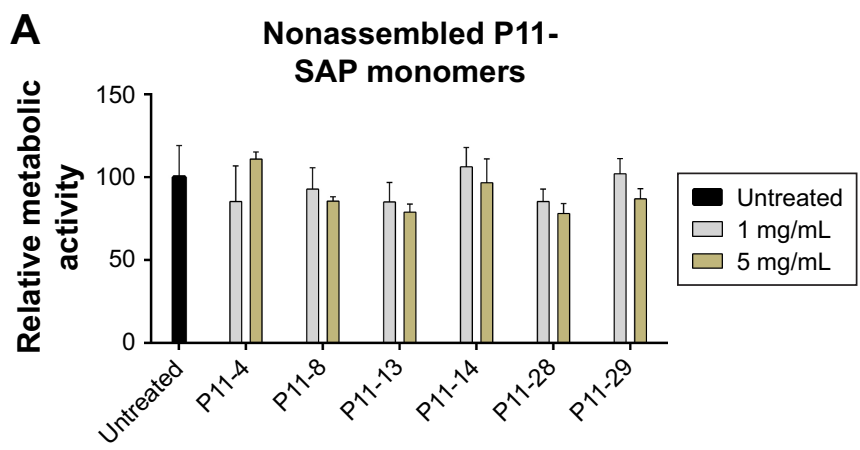

B

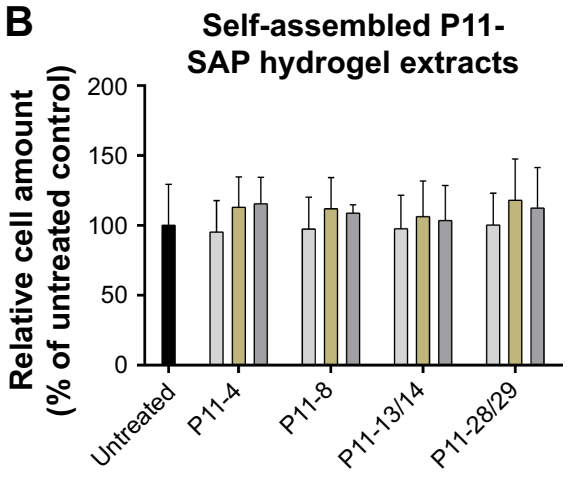

C

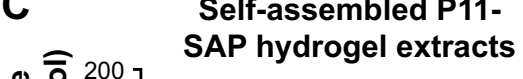

Self-assembled P11

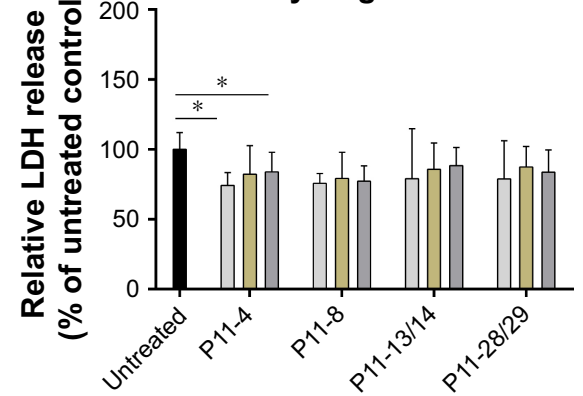

Untreated $\square 1 \mathrm{mg} / \mathrm{mL} \square 5 \mathrm{mg} / \mathrm{mL} \square 10 \mathrm{mg} / \mathrm{mL}$

Figure SI Testing cytocompatibility of monomeric PI I-SAP solution and extracts of PI I-SAP hydrogels in HCO.

Notes: (A) Metabolic activity of HPDLF exposed for 24 hours with the PII-SAP monomers (concentrations: I and $5 \mathrm{mg} / \mathrm{mL}$, PrestoBlue ${ }^{\circledR}$ Cell Viability Reagent, in percent compared with untreated control, $\mathrm{n}=3$ ). (B) Cell amount of HPDLF cells exposed to extraction products of different PII-SAP hydrogels (after 24 hours, I, 5, and I0 mg/mL, in percent compared with untreated control, $n=3$, determined by crystal violet staining). (C) LDH release of HPDLF cells exposed to extraction products of PII-SAP hydrogels (after 24 hours, I, 5, and $10 \mathrm{mg} / \mathrm{mL}$, in percent compared with untreated control, $\mathrm{n}=3, * P \leq 0.0 \mathrm{I}$, measured with LDH cytotoxicity test kit).

Abbreviations: HCO, human calvarial osteoblasts; HPDLF, human periodontal ligament fibroblast; LDH, lactate dehydrogenase; PII-SAP, I I-amino acid self-assembling peptide.

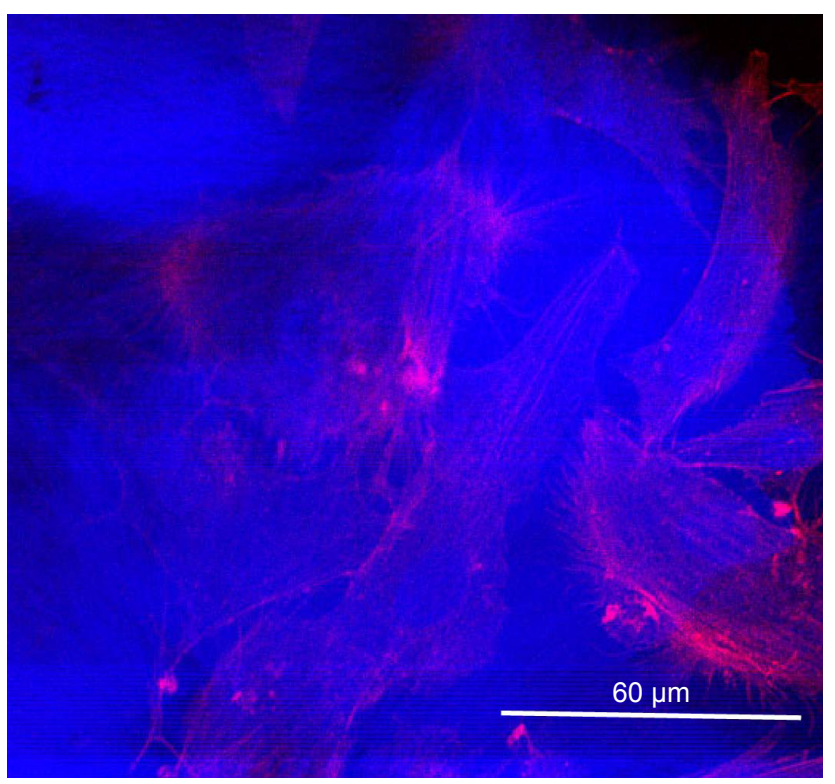

Figure S2 Representative image of the autofluorescence of PI I-SAP hydrogels when cells were fluorescently stained for the F-actin with tetramethylrhodamine isothiocyanate (red, excitation $555 \mathrm{~nm}$, emission $580 \mathrm{~nm}$ ) and the cellular DNA by DAPI (blue, excitation $358 \mathrm{~nm}$, emission $46 \mathrm{I} \mathrm{nm)} \mathrm{(HPDLF} \mathrm{after} 24$ hours growth on a PI I-8 hydrogel). Abbreviations: HPDLF, human periodontal ligament fibroblast; PI I-SAP, I I-amino acid self-assembling peptide. 

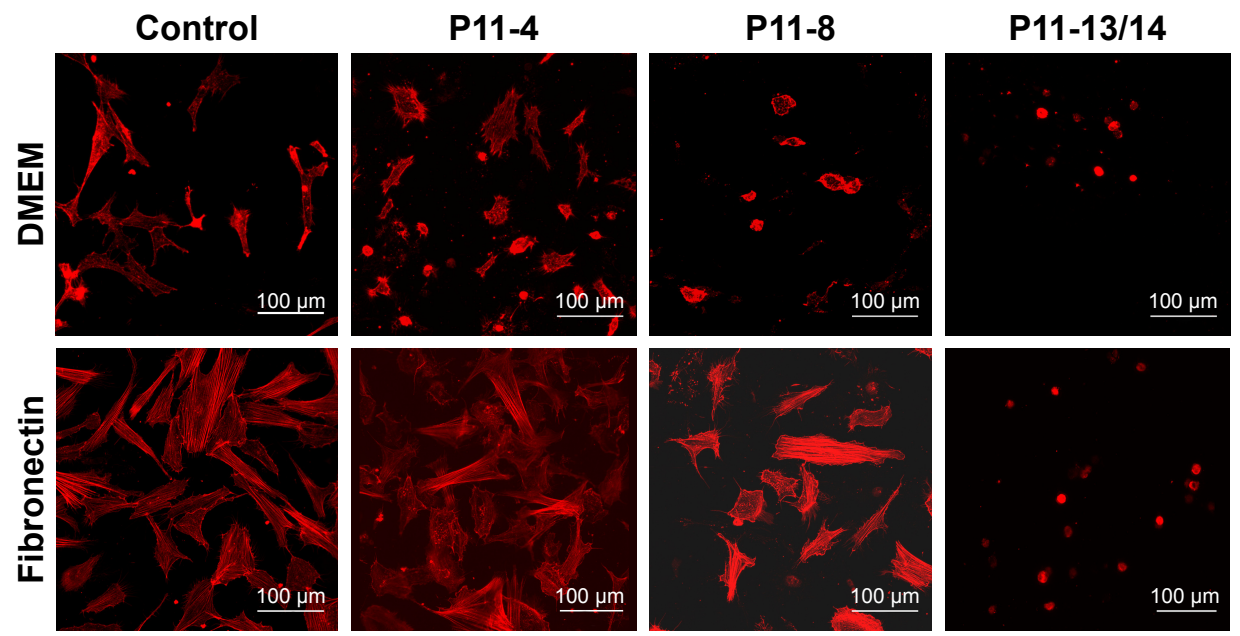

\section{P11-28/29}
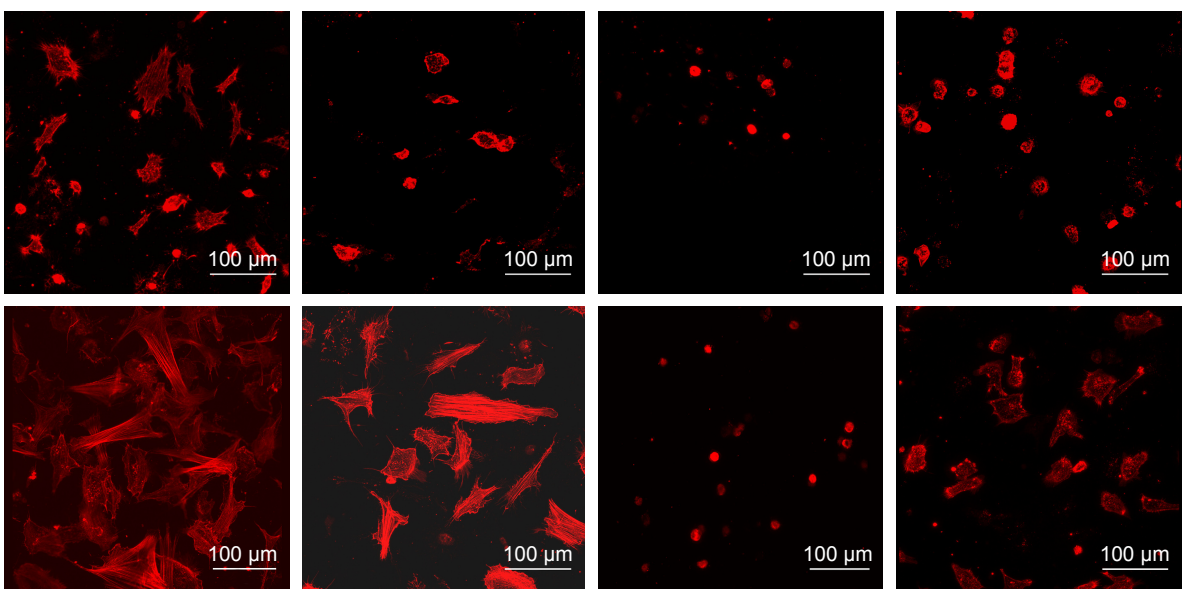

Figure S3 Fibronectin coating of PI I-SAP hydrogels.

Notes: Fluorescent depiction of the actin cytoskeleton of HCO cultured for 24 hours on PII-SAP hydrogels under noncoated/serum-free condition or precoated with fibronectin (confocal microscopy, fibronectin concentration $300 \mu \mathrm{g} / \mathrm{mL}$, scale bar $100 \mu \mathrm{m}$ ).

Abbreviations: $\mathrm{HCO}$, human calvarial osteoblasts; PI I-SAP, I I-amino acid self-assembling peptide.

\section{Publish your work in this journal}

The International Journal of Nanomedicine is an international, peerreviewed journal focusing on the application of nanotechnology in diagnostics, therapeutics, and drug delivery systems throughou the biomedical field. This journal is indexed on PubMed Central, MedLine, CAS, SciSearch $®$, Current Contents $\AA /$ Clinical Medicine,
Journal Citation Reports/Science Edition, EMBase, Scopus and the Elsevier Bibliographic databases. The manuscript management system is completely online and includes a very quick and fair peer-review system, which is all easy to use. Visit http://www.dovepress.com/ testimonials.php to read real quotes from published authors.

\footnotetext{
Submit your manuscript here: http://www.dovepress.com/international-journal-of-nanomedicine-journal
} 